Portland State University

PDXScholar

$5-22-1995$

\title{
The Effectiveness of the Phonological Cycling Approach in Treating an Unintelligible Child in the First Two Cycles of Intervention
}

Anne Cole

Portland State University

Follow this and additional works at: https://pdxscholar.library.pdx.edu/open_access_etds

Part of the Speech and Rhetorical Studies Commons

Let us know how access to this document benefits you.

Recommended Citation

Cole, Anne, "The Effectiveness of the Phonological Cycling Approach in Treating an Unintelligible Child in the First Two Cycles of Intervention" (1995). Dissertations and Theses. Paper 4897.

https://doi.org/10.15760/etd.6773

This Thesis is brought to you for free and open access. It has been accepted for inclusion in Dissertations and Theses by an authorized administrator of PDXScholar. Please contact us if we can make this document more accessible: pdxscholar@pdx.edu. 


\section{THESIS APPROVAL}

The abstract and thesis of Anne Cole for the Master of Science in Speech Communication: Speech and Hearing Science were presented May 22, 1995, and accepted by the thesis committee and the department.

COMMITTEE APPROVALS:

Mary Gordon-Brannan, Chair

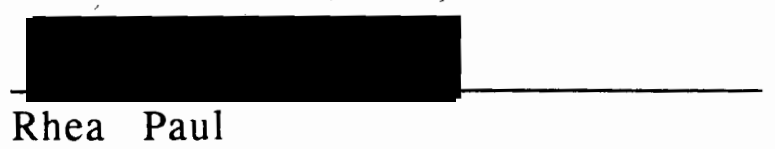

DEPARTMENT APPROVAL:

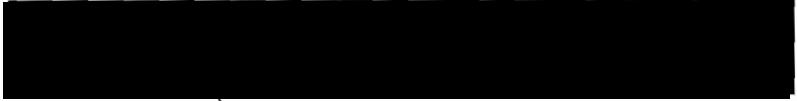

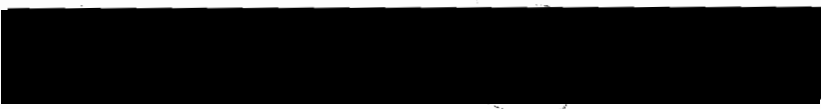

Cathleen Smith

Representative of the Office of

Graduate Studies

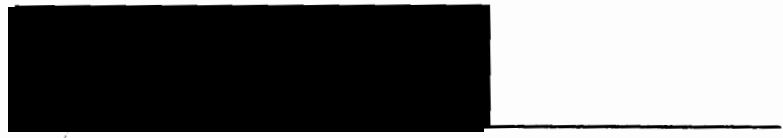

Rhea Paul, Acting Chair

Department of Speech Communication

ACCEPTED FOR PORTLAND STATE UNIVERSITY BY THE LIBRARY

by

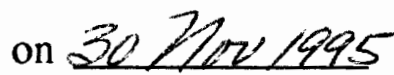




\begin{abstract}
An abstract of the thesis of Anne Cole for the Master of Science in Speech Communication: Speech and Hearing Science Presented May 22, 1995.
\end{abstract}

Title: The Effectiveness of the Phonological Cycling Approach in Treating an Unintelligible Child in the First Two Cycles of Intervention.

One preschool male who was highly unintelligible was enrolled in two cycles of direct intervention utilizing the phonological cycling approach (Hodson \& Paden, 1991). Prior to treatment in cycles 1 and 2, the Assessment of Phonological Processes-Revised (APP-R) (Hodson, 1986) was administered to the subject to assess phonological deficiencies and to determine the target phonological patterns. A continuous speech sample was collected prior to cycle 1 to rate speech intelligibility. Based on the results obtained from the APP-R, target patterns, target words, and an individualized treatment plan were developed for each cycle.

For the first cycle of intervention, the subject participated in 60 minutes of direct intervention twice a week for 5 weeks, and in cycle 2 , the subject participated in 60 minutes of direct intervention twice a week for 4 1/2 weeks. Each treatment session followed the procedures as outlined by Hodson and Paden (1991). Baseline measures were administered at the beginning of each 
session and probes were administered once a week. At the conclusion of both cycles, the APP-R was re-administered and a 100-word speech sample was collected.

The results of the pre- and post-tests for cycles 1 and 2 , baseline measures, weekly probes, and the intelligibility ratings were analyzed to determine the effectiveness of the phonological cycling approach in achieving a decrease in severity level of unintelligibility after two cycles. Results from the APP-R indicate that the subject's severity interval rating decreased from profound to severe. A comparison of pre- and post-intelligibility ratings showed an increase in intelligibility of 1.5 points on a 7-point rating scale. Based on the probes, generalization to nontreatment words in targeted and nontargeted patterns was noted in both cycles for some patterns. Overall, the phonological cycling approach was effective in achieving a decrease in severity level of intelligibility after two cycles of intervention for this subject. 
THE EFFECTIVENESS OF THE PHONOLOGICAL CYCLING APPROACH IN TREATING AN UNINTELLIGIBLE CHILD

IN THE FIRST TWO CYCLES OF INTERVENTION

by

ANNE COLE

A thesis submitted in partial fulfillment of the requirements for the degree of

\author{
MASTER OF SCIENCE \\ in \\ SPEECH COMMUNICATION: \\ SPEECH AND HEARING SCIENCE
}

Portland State University

1995 


\section{ACKNOWLEDGEMENTS}

First, I would like to thank the subject and his mother who participated in this study. Both were wonderful to work with and extremely dedicated to each session. They helped to make the collection of the data fun and easy.

I want to thank and acknowledge Mary Gordon-Brannan, my thesis advisor, for all the support and encouragement she gave me throughout the entire thesis process. She was a wonderful mentor. The time, energy, and effort that she gave are much appreciated.

I want to recognize and thank Rhea Paul and Cathleen Smith, members of my thesis committee. Their questions, insights, ideas, and comments were helpful and appreciated. 


\section{TABLE OF CONTENTS}

ACKNOWLEDGEMENT ......................................................................... i

LIST OF TABLES .................................................................................. v

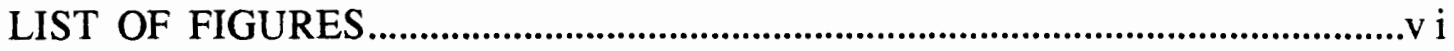

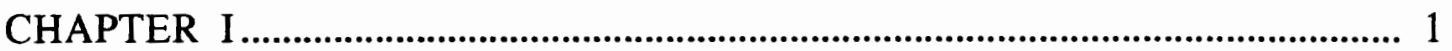

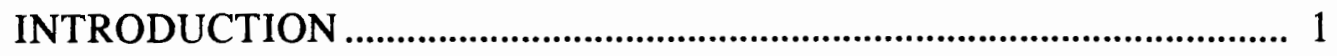

Statement of Purpose ............................................................. 3

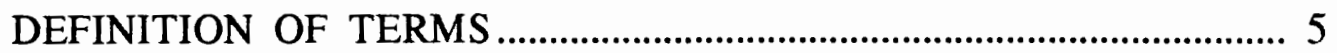

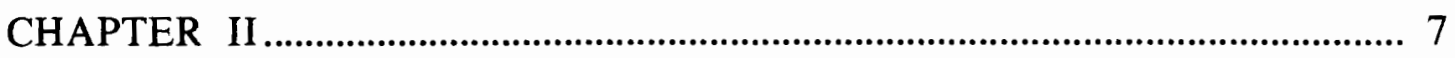

REVIEW OF THE LITERATURE ....................................................... 7

Speech Intelligibility............................................................ 7

Severity Rating Measures............................................. 7

Intelligibility Measures................................................... 9

Intelligibility and Phonological Deviations............. 9

Phonological Approaches and Intervention........................10

Contrasting Pairs Approach...........................................1 1

Phonological Cycling Approach......................................12

Effectiveness of the Phonological Approaches...................14

Contrasting Pairs...............................................................14

Phonological Cycling Approaches.................................16

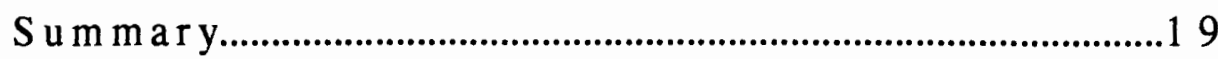

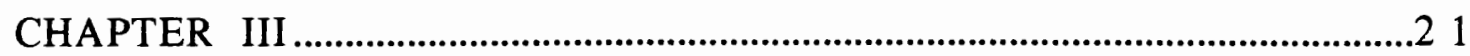

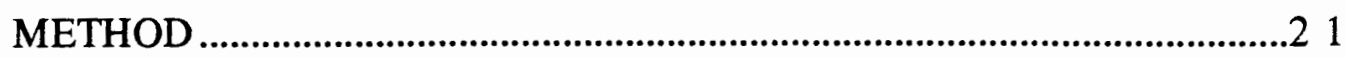

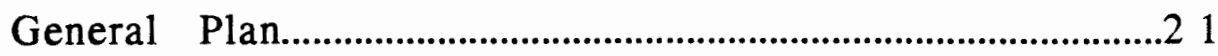

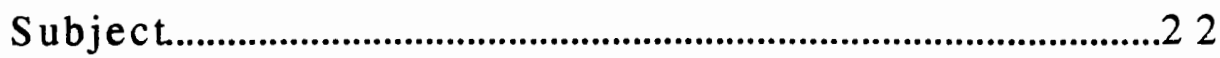




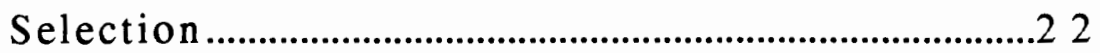

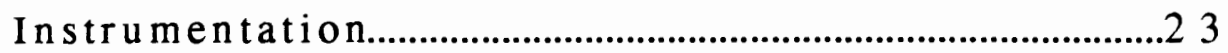

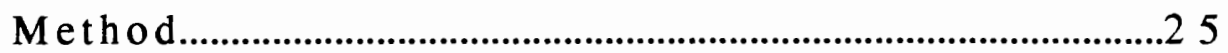

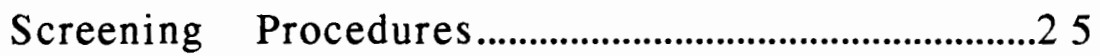

Testing Environment.............................................25

Test Administration ..........................................25

Experimental Procedures.........................................26

Experimental Environment...............................27

Intervention Procedures......................................2 7

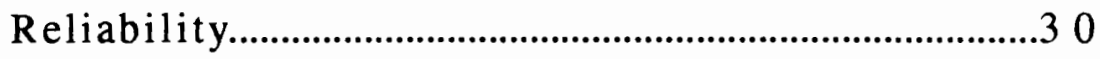

Assessment of Phonological Processes-

Revised................................................................

Speech Samples.......................................................3 0

Data Measurement and Analysis.........................................3 0

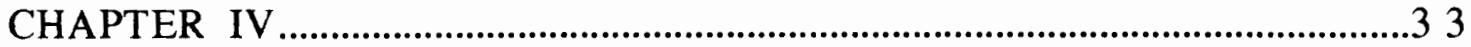

RESULTS AND DISCUSSION .................................................................. 3

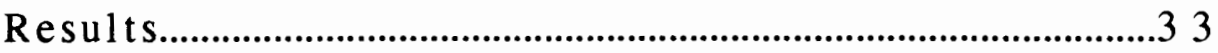

Pre- and Post-Test Measures......................................3 3

Phonological Process Analysis ...........................33

Speech Intelligibility..............................................36

Baseline Measures.............................................................. 37

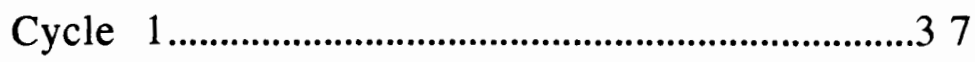

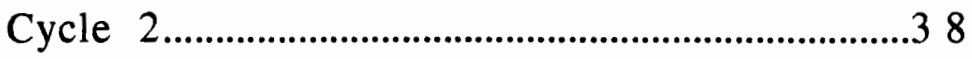

Probes....................................................................................4 1

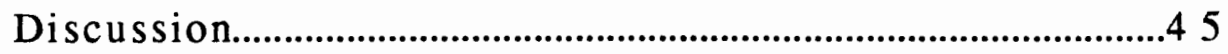

Other Considerations.........................................................4 9 
iv

CHAPTER V ..........................................................................................5 1

SUMMARY AND IMPLICATIONS .............................................5 1

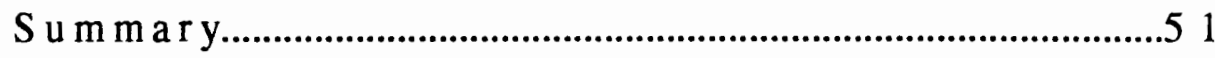

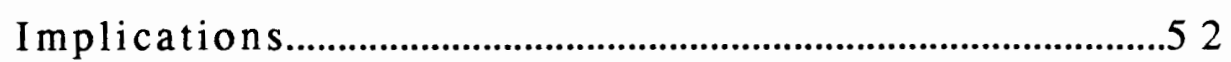

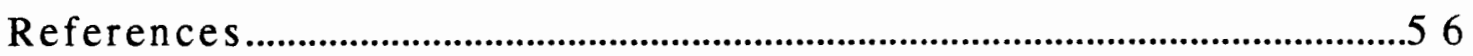

APPENDIXES

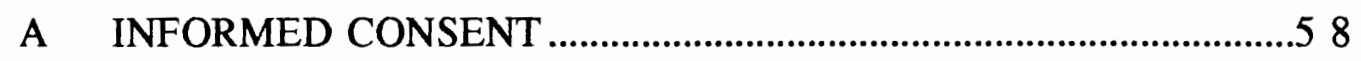

B RATING SCALE FOR INTELLIGIBILITY .............................6 1

C EACH SESSION'S TARGET SOUND AND WORDS FOR

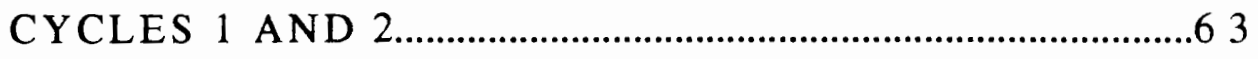




\section{LIST OF TABLES}

\section{TABLE}

1 Results of the Computer Analysis of

Phonological Processes................................................2 4

2 Target Phonological Patterns and Sounds

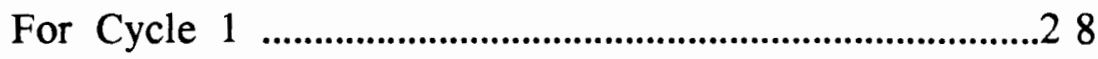

3 Target Phonological Patterns and Sounds

For Cycle 2..................................................................29

4 Pre- and Post-Cycle Results of the Computer

Analysis of Phonological Processes ........................34

5 Intelligibility Ratings for Pre- and Post

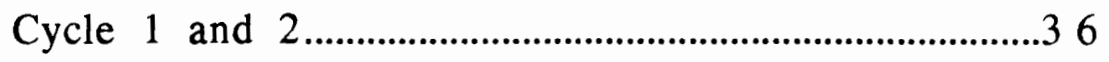

6 Analysis of Cycle 1 Probe List With Treatment

and Nontreatment Words and Patterns...................4 2

7 Analysis of Cycle 2 Probe List With Treatment

and Nontreatment Words and Patterns..................44 


\section{LIST OF FIGURES}

FIGURE

1 Cycle 1 Baseline for Initial $/ \mathrm{m} /$, Initial

$/ \mathrm{n} /$, and Final $/ \mathrm{n} /$

2 Cycle 1 Baseline for $/ \mathrm{st} /, / \mathrm{sp} /, / \mathrm{sk} /, / \mathrm{ks} /$,

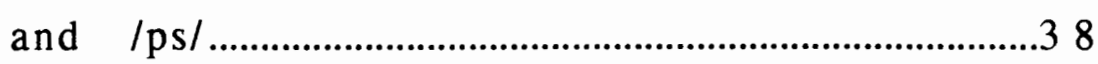

3 Cycle 1 Baseline for Initial $/ 1 /$ and Initial $/ \mathrm{r} / \ldots \ldots \ldots \ldots \ldots \ldots . . . .39$

4 Cycle 2 Baseline for Initial $/ m$, $n /$, Final $/ \mathrm{n} /$,

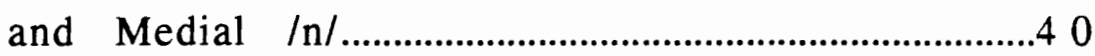

5 Cycle 2 Baseline for $/ \mathrm{sk} /, / \mathrm{sp}$, st/, and $/ \mathrm{ks}$, ps/.............40

6 Cycle 2 Baseline for Initial $/ 1 /, / \mathrm{pl} /$, and

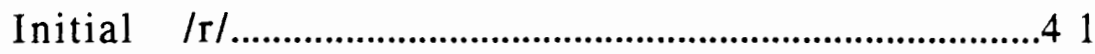




\section{CHAPTER I}

\section{INTRODUCTION}

Within the last 20 years, there has been a shift in the type of intervention approach used for treating children who are highly unintelligible. Until the mid-1970s, speech disorders were viewed as a result of a phonemic inadequacy in which the child was unable to articulate sounds correctly (Hodson \& Paden, 1991). Because the incorrect production of phonemes was considered the result of learning and control of the articulators, traditional articulation approaches have focused on teaching children how to move the articulators in a rapid and precise manner (Fey, 1992). A major component in the phoneme-oriented approach is the motor training of each and every error phoneme. Typically the error phonemes are targeted one-by-one in all positions such that accurate production of each phoneme in all positions is the goal of the phoneme-oriented approach.

While traditional phoneme-oriented approaches are primarily concerned with the motoric aspects of speech production, a broader concept, phonology that refers to the speech sound system of a language, has been embraced. Phonology involves the classification and organization of speech sounds and how they undergo changes when they occur in different contexts (Hodson \& Paden, 1991). More recently, phonological approaches have emerged that encompass all aspects of the sound system. Rather than focusing on individual phonemes, this approach takes advantage of the systematic nature of speech deviations (Hodson \& Paden, 1991). 
Because children's errors are considered to spread to sounds that are similar in phonological features, phonological patterns that are deficient are targeted. The goal of this approach is to facilitate the emergence of phonological patterns, specific phonemes and sequences, that contribute to intelligibility.

Intelligibility and phonological proficiency have been found to be closely related. Children with phonological disorders must learn to produce speech that is intelligible. Typically, the speech of children who are unintelligible is characterized by phonological deviations, such as cluster reduction, stridency deletion, stopping, and assimilation (Hodson \& Paden, 1981). When speech is characterized by such phonological processes, intelligibility is often compromised because the speaker's message might not be understood.

The phonological cycling approach developed by Hodson and Paden (1991) is an intervention approach designed for working with children who are unintelligible. This approach is based on the concept that even the most disordered speech has its own structure. Since the cycling approach takes advantage of the systematic nature of speech deviations, sound patterns that are in error are taught rather than individual sound errors. In order to teach sound patterns, cycles are used to facilitate the emergence of intelligible speech patterns. The cycling approach was developed because it was recognized that normally developing children do not master one sound or sound pattern before learning another. Rather, there is a great deal of experimentation with sounds and patterns before 
they are mastered. The cycling approach takes advantage of the way in which a phonology develops. Phonemes within patterns are used to facilitate the emergence of the phonological pattern. In the traditional approach, individual sounds are taught until a specific level of accuracy is reached. In the cycling approach, a pattern is targeted for approximately 2 to 5 hours before preceding to the next target pattern. This allows the child to focus on that particular pattern.

Although studies have indicated that the cycling approach is effective with modifications, there have been few efficacy-based studies on the unmodified cycling approach (Hodson, 1992a; Montgomery \& Bonderman, 1989; Tyler, Edwards, \& Saxman, 1987). Since empirical data regarding the effectiveness of the cycling approach based on Hodson and Paden's (1991) guidelines are minimal, research specifically designed to investigate the effectiveness of Hodson and Paden's approach with highly unintelligible children is needed.

\section{Statement of Purpose}

This study was designed to investigate the effectiveness of the first two cycles of the phonological cycling approach developed by Hodson and Paden (1991) with a child who was unintelligible. This study investigated whether treatment with the cycling approach leads to: (a) a decrease in severity level as indicated by the phonological deviance score on the Assessment of Phonological Processes-Revised (APP-R; Hodson, 1986), and (b) an increase in overall intelligibility as rated by trained listeners. The research 
hypothesis was: The phonological cycling approach will lead to a significant decrease in severity level after two cycles of intervention as measured by pre- and post-testing on the APP-R and by pre- and post-intelligibility ratings. 


\section{DEFINITION OF TERMS}

The following terms were used for this investigation. The phonological terms were derived from Hodson and Paden (1991).

Consonant Sequences- The omission of one or more sound segments in a consonant cluster, e.g., /mok/ for "smoke".

Generalization- Using a target pattern in untrained words, word positions, or conditions.

Glide Deficiency- A glide sound /w, $\mathrm{j} /$ is omitted or substituted for by a nonglide sound, e.g., /IElo/ for "yellow".

Liquid (1) Deficiency- An /1/ sound is omitted or substituted for by another sound, e.g., /wat/ for "late".

Liquid ( $r$ ) Deficiency- An /r, , / sound is omitted or substituted for another sound, e.g., /wen/ for "rain".

Nasals- The nasal sound $/ m, n, n /$ is omitted or substituted for by a non-nasal sound, e.g., /doz/ for "nose".

Postrocalic Singletons- The omission of a single consonant that ends a word or syllable, e.g., /bo/ for "boat".

Prevocalic Singletons- The omission of a single consonant that initiates a word or syllable, e.g., /Ig/ for "pig".

Strident Deficiency- A strident sound /f, v, s, z, , , t, d/ are omitted or substituted for by a nonstrident sound, e.g., /top/ for "soap".

Syllable Reduction- The omission of a syllable in the production of a target word, e.g., /teto/ for "potato". 
Velar Deficiency- A velar sound $/ \mathrm{k}, \mathrm{g} /$ is omitted or substituted for by a nonvelar sound, e.g., /tau/ for "cow". 
CHAPTER II

\section{REVIEW OF THE LITERATURE}

Speech Intelligibility

Intelligibility can be defined as how well an individual is understood by listeners. It is usually expressed as a percentage of speech understood by a listener and can be influenced by the context, production of speech sounds, linguistic structures, and suprasegmentals (Shriberg \& Kwiatkowski, 1982; Weiss, Gordon, \& Lillywhite, 1987). Intelligibility of speech is usually reflected on a severity rating scale. Terms such as mild, moderate, severe, and profound are typically used to classify the severity of speech disorders (Hodson, 1986; Hodson \& Paden, 1991; Shriberg \& Kwiatkowski, 1982; Weiss et al., 1987).

\section{Severity Rating Measures}

A severity rating measure that has proven to correlate with intelligibility can be derived from the APP-R. From this phonological assessment instrument, involving the elicitation of 50 words produced spontaneously, the phonological deviations that a child uses in speech production are identified. In addition, a severity rating of mild, moderate, severe, or profound is assigned to the child's phonological deviancy average. The severity rating reflects the types and quantity of phonological deviations used, and the child's repertoire of consonants as well as the child's age. Based on speech samples of over 200 children with highly unintelligible speech, Hodson and Paden (1991) reported that children with the least intelligible speech received a severity rating of profound on 
the APP-R. Their speech was characterized by extensive omissions, that is, the deletion of a consonant, and some substitutions, that is, substituting one consonant for another. In addition, Hodson and Paden reported that children who received a severity rating of profound had an extremely restricted repertoire of consonants. Children with slightly more intelligible speech received a severity rating of severe, and more substitutions and fewer omissions were noted. While children in the severe range produced more consonants, the number of consonants they produced was still quite restricted. This suggests that intelligibility is greatly related to the severity rating assigned to a child's speech.

Another severity rating measure that correlates with intelligibility measures is the Percentage of Consonants Correct (PCC). Shriberg and Kwiatkowski (1982) reported that the PCC value obtained from a continuous speech sample reflects a severity rating that incorporates disability, intelligibility, and handicap. Because the PCC severity rating measure incorporates these areas, the PCC value can be used to classify the severity of a phonological disorder. The procedure for achieving a PCC value is based on correct and incorrect productions of consonants in a continuous speech sample. Severity levels of mild, mild-moderate, moderatesevere, and severe are assigned based on the PCC value. The greater the number of incorrect consonants, the more severe the phonological disorder. As the number of consonants correct increases, the severity rating decreases. Therefore, the greater the number of consonants used correctly, the more intelligible the 
speech (Shriberg \& Kwiatkowski, 1982). This suggests that intelligibility is greatly affected by the number of incorrect consonants. It appears that phonological disorders that are characterized by omissions and substitutions, that is, substituting one consonant for another, affect intelligibility.

Intelligibility Measures

Although the APP-R and PCC have been found to correlate with intelligibility, other approaches directly measure intelligibility (Gordon-Brannan, 1994). Three general approaches for the measurement of intelligibility are open-set word identification, closed-set word identification, and rating scale procedures (GordonBrannan, 1994). The open-set word identification procedure involves calculating the percentage of words understood in a conversational speech sample (Weston \& Shriberg, 1992). In the closed-set word identification procedure, words spoken are selected by the listener from a word list. In the rating scale approach, an interval scaling procedure is often used in which the listener assigns a number to a speech sample based on perceived intelligibility. Five-point, seven-point, and nine-point rating scales have been used to rate intelligibility. For example, on a seven-point rating scale, a rating of 1 may be considered essentially unintelligible and a rating of 7 may be considered essentially intelligible.

Intelligibility and Phonological Deviations

According to Kent (1991), intelligibility and phonology are strongly linked. Children who are unintelligible use cluster 
reduction, stridency deletion, stopping, and assimilations (Hodson \& Paden, 1981). In contrast, very few children who are intelligible use these deviations. In addition, some of the children who are unintelligible use one or more of the following deviations: final consonant deletion, fronting of velars, backing, syllable reduction, prevocalic voicing, and glottal replacement. These same deviations were almost nonexistent in the speech of typically developing intelligible children (Hodson \& Paden, 1981). Therefore, if a child fails to produce the phonological patterns of the language correctly, intelligibility may be compromised because the speaker's message might not be understood.

Gordon-Brannan (1994) suggested that when planning intervention for a child with a phonological disorder, two intelligibility measures, such as a seven-point rating scale, and severity rating measures, such as the APP-R, should be used. These measures provide information for determining the intelligibility and severity of a speech disorder, thus giving a "picture" of the child's communication competence (Gordon-Brannan, 1994). In addition to being important for planning and implementing intervention, the measures can also be used to evaluate the effectiveness of the intervention approach.

Phonological Approaches and Intervention

The phonological approach has emerged to treat children who are highly unintelligible. This approach takes advantage of the systematic nature of speech deviations and focuses on the suppression of phonological deviations that contribute to 
unintelligibility. Two phonological approaches that are utilized when working with children who are unintelligible are the contrasting pairs approach and the phonological cycling approach. Contrasting Pairs Approach

Contrasting pairs refers to the differentiation of pairs of phonemes by a specific feature for the purpose of signaling a difference in meaning. For example, the phonemes $/ d /$ and $/ \mathrm{t} /$ differ only in the voicing feature as in the words den and ten. There are two types of intervention programs involving contrasting pairs: minimal pairs and maximal opposition. Both treatments compare, in the context of words, a sound that is in the child's sound system to a sound that is not used by the child. The goal of both treatments is to teach a child sound pairs that illustrate a contrast. By learning the differences between the two sounds and using the two sounds, the occurrence of homonymy in the sound system is reduced. In addition, both treatments use pairs of words in which one or more of the sound features are different. When the child's speech-sound error is produced, these words become homophones (Saben \& Ingham, 1991). For example, if a child uses the phonological process of postvocalic deletion, bee and beet could be considered a minimal pair.

Although the two contrasting treatments share similarities, they differ in the number of features that are contrasted. In minimal pairs treatment, the sounds that are contrasted share all the same features except one. The phonemes $/ \mathrm{p} /$ and $/ \mathrm{b} /$ could be contrasted when targeting voicing because they differ only in the 
voicing feature. However, in maximal opposition, as many features as possible are contrasted. For example, the phonemes $/ \mathrm{s} /$ and $/ \mathrm{m} /$ could be contrasted because they differ in voicing, manner (i.e., stridency and nasality), and place of articulation (i.e., alveolar and labial).

Contrasting pairs confront children with phonemic contrasts that result from speech-sound changes (Saben \& Ingham, 1991). Strategies, such as games designed to create confusing communication situations, are used to show children that their misarticulations result in miscommunication. Therefore, contrasting pairs enhance the feature that children need to learn and teach children to make phonemic contrasts in their speech in order to differentiate meanings (Saben \& Ingham, 1991).

Phonological Cycling Approach

Another intervention approach that suppresses phonological processes is the phonological cycling approach. This approach, developed by Hodson and Paden (1991), focuses on phonological processes that affect a child's intelligibility. Phonological patterns are targeted to facilitate a broader learning of speech sounds and to encourage the development of phonological patterns. For example, if a child deletes final consonants, voiceless final stops $/ \mathrm{t}, \mathrm{p} /$ would be taught for 2 hours to help the child learn to close syllables (Hodson \& Paden, 1991). By concentrating on phonemes within a sound pattern, this approach stimulates a child's ability to generalize. 
Potential target phonological patterns are identified by a phonological assessment, such as the APP- $R$ (Hodson, 1986). When target patterns have been identified, they are targeted utilizing the cycling approach (Hodson \& Paden, 1991). In the cycling approach, syllables, phonemes, or consonant clusters within a target pattern are targeted for 60 minutes. Each target pattern is targeted for approximately 2 to 5 hours before preceding to the next target phonological pattern. Correct production of the target pattern is extremely important. During each session, the words are elicited using whatever cues, that is, tactile, visual, and/or modeling, that are necessary to achieve $100 \%$ accuracy of the target pattern. Each session follows the procedures outlined in Hodson and Paden (1991). They include:

1. Review of preceding session's production-practice words.

2. Auditory bombardment.

3. Potential word list for production practice words selected carefully for facilitative phonetic environments.

4. Production-practice activities.

5. Probing to obtain next session's production-practice words.

6. Auditory bombardment.

7. Home practice words and listening word list.

When each pattern has been targeted, a cycle has been completed. At this time, the phonological assessment is 
readministered to determine the progress made and to identify the phonological patterns to target in cycle two. Most patterns are presented again and the complexity of the phonetic environment surrounding the target pattern is increased. Cycling continues until the child achieves intelligibility.

Effectiveness of the Phonological Approaches

Since the contrasting pairs approach and the phonological cycling approach are used in treating children who are unintelligible, studying the effectiveness of each approach in achieving intelligibility is of crucial importance. A few studies focusing on the effectiveness and efficiency of both approaches have been conducted to determine whether or not they are effective in achieving a decrease in severity levels.

\section{Contrasting Pairs}

Maximal opposition. In 1990, Gierut conducted a study to evaluate whether the structure of minimal versus maximal pairs would result in empirical differences in phonological acquisition. Three boys, age 4, participated in the study and received intervention in both minimal pairs and maximal opposition for two independent sound pairs. Both treatments and sound pairs were taught within each treatment session. Results of this study indicated that maximal opposition enhanced the learning of treated sounds better than minimal pairs. Two of the three children showed differential learning of the contrasted sounds with better performance observed under the maximal opposition treatment. Therefore, maximal opposition appeared to facilitate the learning of 
treated sounds. Maximal oppositions also provided for changes in untreated words that expanded the child's sound system. Minimal pair contrasts did not lead to the same changes in untreated sounds. In terms of the number of sounds added, each subject evidenced a greater number of sounds in their inventories under the maximal oppositions treatment. Under minimal pairs treatment, only one subject added a new sound to his inventory. Although both types of contrast treatments affected change in the child's phonological systems, maximal oppositions provided a greater impact for change and facilitated more extensive sound learning.

Minimal pairs. The minimal pairs approach has been found to be effective in reducing the frequency of phonological processes. According to Weiner (1981), both subjects who participated in his study changed their productive systems without direct articulatory training. In this study, potentially confusing communication situations were set up to confront the subjects that their misarticulations were resulting in miscommunications. However, when the subjects failed after two consecutive attempts to make the appropriate changes in their speech-sound productions, models and/or instructions were given so that the correct sound could be made. Weiner (1981) reported that this method seemed to be effective because the frequency of phonological processes was reduced and generalization of the treatment task to non-treatment words occurred.

Although Weiner (1981) reported success of the minimal pairs approach in reducing phonological processes, Saben and 
Ingham (1991) reported that both subjects in their study involving the minimal pairs approach failed to generalize the speech sounds of treated phonemes to untreated words or to untreated phonemes. They provided several explanations for why the subjects failed to generalize. Failure to generalize to untreated words might have been due to the way in which the minimal pairs were used in intervention. Rather than create a communication breakdown that was shown to be successful in Weiner's study, in this study, the subjects were made aware of homophones. In addition, the assumption that children change their speech sound production when confronted with the homonyny that results from their speech-sound changes might be faulty. Saben and Ingham (1991) reported that the success of previous studies involving minimal pairs intervention (Weiner, 1981) might have little to do with the minimal pairs stimuli. Intervention steps in Weiner's study involved other components, such as motor training, rather than just using minimal pairs. Since the effectiveness of the minimal pairs approach in training children with phonological disorders has yet to be determined, Saben and Ingham (1991) concluded that further research is needed.

\section{Phonological Cycling Approaches}

The effectiveness of Hodson and Paden's (1991) phonological cycling approach with a group of nine unintelligible preschool children was evaluated by Montgomery and Bonderman (1989). The phonological cycling approach was implemented in a group intervention program for two cycles. The children received 
treatment 3 days a week for 2 hours each day. Each cycle was 2 months in length. After the two cycles of intervention, the final assessment indicated that all subjects received lower severity ratings. Seven of the 9 subjects with severe ratings prior to intervention progressed to moderate or mild severity ratings at the end of cycle two. In addition, 4 of the 9 subjects who were judged to be speaking appropriately for their chronological age were dismissed after the two cycles. Results of this study indicated that the approach was highly efficient and effective in achieving a decrease in the severity level in a group intervention setting. Montgomery and Bonderman reported that the success of this approach can be attributed to targeting phonological patterns, group interactions, and a home program. The phonological cycling approach appears to be effective in treating children with severeto-profound speech disorders in groups.

A modified cycles approach, based on Hodson and Paden's (1991) cycling approach, was used to show how this approach could be implemented in the remediation of two unintelligible children. Tyler et al. (1987) adopted Hodson and Paden's basic procedures for perception and production training, but the format for scheduling processes for remediation was modified. Tyler et al. (1987) defined a cycle as being 3 weeks in length. Each week consisted of two 60minute sessions. One process was targeted each week, and two training sounds were chosen for each target process. Each session included Hodson and Paden's "auditory bombardment" procedure, but the word list was read without amplification. For each session, 
5-10 words were carefully selected. In the modified cycles approach, only 3-5 target processes were treated. A home program involving the auditory bombardment list and the picture representing the stimulus word was utilized. Rather than having the children produce the target pattern with $100 \%$ accuracy, Tyler et al. (1987) set a criterion of $20 \%$ or greater. If the child achieved $20 \%$ accuracy or less, the second session for a particular pattern was spent on the same sound. However, if the accuracy of the production was $20 \%$ or more, the next session focused on a different target sound. At the end of the 3 weeks, the cycle was repeated using the same training sounds and stimulus words rather than different stimulus words. Results from the study indicated that the modified cycles approach was effective and efficient in suppressing the phonological processes used by the children in two cycles of intervention. In addition, generalization of the target pattern to untrained sounds affected by the phonological process occurred.

Although effectiveness of the phonological intervention approach is an important consideration, time and academic skills are also major concerns in determining the effectiveness of an intervention approach. Hodson (1992a) reported that it often takes highly unintelligible children 6 years to become intelligible when learning with a phoneme-by-phoneme approach. In addition, these children often fall behind their peers in the development of academic skills (Hodson, 1992a). While traditional approaches are too restrictive for unintelligible children because the correct 
production of a phoneme must be learned before preceding to the next, phonological-based approaches provide a broader framework for achieving intelligibility by facilitating the emergence of phonological patterns. University clinics that have implemented the phonological cycling approach have reported that most children who were admitted as highly unintelligible were dismissed within a year having achieved intelligibility (Hodson, 1992a). This method appears to be efficient in achieving intelligibility, but no empirical data have been reported in the literature for the approach implemented exactly as Hodson and Paden (1991) have outlined for individual intervention.

Although researchers have used the cycling approach and it has proven to be effective with modifications, there have not been efficacy-based studies on the cycling approach (Hodson, 1992a; Montgomery \& Bonderman, 1989; Tyler et al., 1987). Past studies have modified Hodson and Paden's (1991) cycling approach in some way. Therefore, data regarding the efficiency of the approach based on Hodson and Paden's (1991) guidelines are lacking. Because of this, research specifically based on Hodson and Paden's cycling approach is needed. According to Hodson and Scudder (1990), more research is needed to investigate the efficiency of the cycling approach with children who are highly unintelligible. Factors such as severity, hours of contact time, and generalization to non-treatment words and patterns must be considered. Investigation of these factors will help determine the effectiveness of the intervention approach. 
Su m mary

Specific phonological deviations are found in the speech of unintelligible children. These deviations, such as cluster reduction and stridency deletion, have been found to affect intelligibility adversely (Hodson \& Paden, 1981). Severity ratings, such as the APP-R (Hodson, 1986) and the PCC (Shriberg \& Kwiatkowski, 1982) have proven to correlate with intelligibility. These ratings indicate that the least intelligible speech, characterized by phonological deviations and absent or incorrect consonants, receive severity ratings of profound or severe. This suggests the severity rating of a child's speech is greatly affected by the types and quantity of phonological processes used, and by the child's repertoire of consonants.

Children who are highly unintelligible experience a communication deficit that needs to be eliminated or significantly reduced as soon as possible because requisite communication skills are necessary for academic and social success. Finding an intervention approach that will yield quick intelligibility gains is critical for children who are highly unintelligible. While past studies have revealed the cycling approach to be effective in achieving intelligibility, in all studies the approach was modified in some way. Research into the effectiveness of the cycling approach without any modification is needed. The phonological cycling approach was chosen for this study to investigate the effectiveness of this approach in achieving a decrease in severity level in the first two cycles of intervention with a child who was unintelligible. 


\section{CHAPTER III}

\section{METHOD}

\section{General Plan}

This study was conducted at the Portland State Speech and Hearing Clinic in Portland, Oregon. One subject, a preschool male aged $31 / 2$ years who was unintelligible, participated in the study. The subject received two cycles, approximately 5 weeks in length each, of direct intervention utilizing the phonological cycling approach delievered by the author.

A multiple baseline across behaviors procedure was the treatment design for this study. The multiple baseline procedure allowed for the evaluation of whether or not change was due to intervention. Baseline measures were obtained for each target pattern. At the beginning of each session, baseline measures were obtained on the target phonological patterns which was accomplished by eliciting imitated responses to two treatment words and two non-treatment words that contained the target pattern.

A probe, consisting of imitated treatment words, nontreatment words with the targeted pattern, and words with nontargeted patterns, was administered every week during intervention. Probes allowed for the evaluation of generalization to non-treatment words. Prior to intervention and at the end of each cycle, a phonological processes test was administered by the author to assess improvement and determine the target phonological patterns for cycles one and two. Continuous speech samples elicited 
prior to intervention and at the end of each cycle were rated by 2 unfamiliar listeners for intelligibility in order to assess improvement. The results of the pre- and post-tests, baseline measures, weekly probes, and the intelligibility rating scales were compared to determine the effectiveness of the phonological cycling approach in achieving an increase in intelligibility after two cycles.

\section{Subject}

\section{$\underline{\text { Selection }}$}

One preschool male was selected from current applications of children seeking services at the Portland State Speech and Hearing Clinic. Prior to intervention, the child had not received treatment with the phonological cycling approach or any other approach for the speech disorder. The subject met all criteria for inclusion in this study:

1. Written permission from the child's parent or guardian acknowledging their child's participation in the study (Appendix A).

2. Between the ages of 42 and 66 months.

3. Standard English as the primary language spoken in the home.

4. Absence of organic or physical deviancy.

5. Normal unilateral hearing defined as passing an audiometric screening at $25 \mathrm{~dB}$ for the following frequencies: 500, 1000, 2000, $4000 \mathrm{~Hz}$. 
6. Receptive language within normal limits as measured by the Peabody Picture Vocabulary Test-Revised (PPVT-R) (Dunn \& Dunn, 1981).

7. Severe or profound phonological disorder as measured by the APP-R.

8. Absence of hoarse, hypernasal, or hyponasal voice qualities.

The first subject tested for this study met all criteria for inclusion; therefore, additional subject selection was not required. The subject selected, a male, was 3 years, 6 months at the beginning of this study, and 3 years, 11 months at the end. On the PPVT-R, administered at the beginning of the study, the subject achieved a raw score of 40 which correlates to a standard score equivalent of 106 and a stanine of 6 . This placed him in the 66th percentile with an age equivalent of 3:11. Overall, he achieved a high average score. Results of the APP-R are illustrated in Table 1.

Instrumentation

A pure-tone audiometric screening test was performed with a portable Beltone audiometer, model 120, ANSI, 1969. The PPVT-R (Dunn \& Dunn, 1981), a measure designed to assess a child's receptive vocabulary, was used to determine eligibility for the study.

The reliability of the PPVT-R appears to be satisfactory. A correlation coefficient median of .80 was attained in the internal consistency measure, and a correlation coefficient median of .82 
Table 1

Results of the Computer Analysis of Phonological Processes (CAPD) (Hodson, 1992b).

\section{OMISSIONS}

Syllables

Prevocalic Singletons

Postvocalic Singletons

Consonant Sequences

\section{CLASS DEFICIENCIES}

Stridents

Velars

Liquid (1)

Liquid (r)

Nasals

Glides 70

Average of Phonological Processes 63

Phonological Deviancy Score 63

was attained in the immediate retest reliability. The delaly retest measure attained a correlation coefficient median of .78 .

The APP-R, a measure that assesses the presence and severity of phonological processes, was the next step in determining eligibility for the study. The results of the APP-R were analyzed 
using the Computer Analysis of Phonological Deviancy (CAPD; Hodson, 1992b).

This computer program, designed to analyze the subject's productions elicited through the APP-R, was performed on an IBMclone computer.

\section{Method}

Screening Procedures

Testing Environment. All testing procedures were administered in a quiet room free from distractions. Testing was conducted at the Portland State Speech and Hearing Clinic, and each test was recorded on audiotape.

Test Administration. Following the hearing assessment, the subject was administered the PPVT- $R$ to determine the presence or absence of a receptive language disorder. The administration of the test followed the instructions as outlined in the test manual.

After administering the PPVT- $R$, the APP- $R$ was administered. Ten basic phonological deviations are assessed in the test. Fifty objects, that elicit the target words, provided the opportunity to analyze 10 phonological processes.

The test was administered according to the APP-R test manual instructions. The 50 objects were presented to the subject in a random order. If he failed to respond or gave an incorrect response, the examiner provided a prompt in order to elicit the correct response. If he still did not respond correctly, a delayed model was provided, such as "Chair. Now you say that." All responses that contained sound errors were phonetically 
transcribed using the APP-R recording sheet. Responses were transcribed at the time of testing by the examiner. The administration of the APP-R was tape-recorded and analyzed by the examiner and another speech-language pathologist to verify or alter the live transcription.

The results of the APP-R were scored using the CAPD. Each transcribed response was entered into the CAPD in order to analyze the 10 basic phonological processes. The analysis of the results yielded a percentage-of-occurrence score for each of the 10 phonological processes, an average phonological processes score, a phonological deviancy score, and a severity interval rating.

\section{Experimental Procedures}

After the subject was selected for the study, a 100-word speech sample was collected by the author to be used for rating his intelligibility. The speech sample was tape-recorded in order to be analyzed after the testing was finished. Speech intelligibility was analyzed by two graduate speech-language pathology students using a seven-point Likert rating scale. The raters were unfamiliar listeners. A rating of 1 was considered essentially unintelligible and a rating of 7 was considered essentially intelligible. The speech intelligibility ratings were conducted in a quiet room. The raters were given written instructions regarding the rating procedures. First, three speech samples representing the intelligibility continuum were presented to the raters in order to provide for practice with the rating system. After the practice samples, the 100-word speech samples were presented in a random 
order. A Panasonic tape recorder (model RQ-L340) and a small Sony speaker (model SR5-150) were used to present the speech samples. The results from each rater were averaged to determine the intelligibility rating score for each sample. The rating scale is found in Appendix B.

Experimental Environment. All intervention sessions were conducted in a quiet room free from distractions. Intervention was conducted at the Portland State Speech and Hearing Clinic.

Intervention Procedures. The computer analysis of the subject's results from the APP-R was used to determine which phonological patterns were chosen as targets. The patterns and sounds selected for cycle 1 are shown in Table 2 . The subject participated in 60 minutes of direct intervention twice a week. Each phonological pattern was targeted for 2 to 5 hours of intervention in each cycle. Each session followed the guidelines outlined by Hodson and Paden (1991). At the beginning of each 60minute session, the previous session's production-practice words were reviewed. Next, auditory bombardment- listening to repetitions of words containing the session's target pattern- is done to facilitate an awareness of target patterns. A Realistic Stereo Amplified Listener (Model 33-1093) was used for the auditory bombardment. New target words were carefully selected for facilitative phonetic environments, and the subject colored pictures of the target words on $5^{\prime \prime}$ by 8 " index cards. These picture cards, with a picture of the target word and the word written on the card, Table 2 
Target Phonological Patterns and Sounds for Cycle 1

\begin{tabular}{ll}
\hline Target Phonological Patterns & Target Sounds \\
\hline Nasals & initial $/ \mathrm{m} /$, initial $/ \mathrm{n} /$, and \\
& final $/ \mathrm{n} /$ \\
Stridency and Consonant & $/ \mathrm{st} /, / \mathrm{sp} /, / \mathrm{sk} /, / \mathrm{ks} /, / \mathrm{ps} /$ \\
Sequences & initial $/ 1 /$ \\
Liquid (l) & initial $/ \mathrm{r} /$ \\
\hline
\end{tabular}

were incorporated into 4-7 experiential-play production-practice activities. Near the end of the session, probing was conducted to determine the best words for the next session's target pattern. Auditory bombardment with slight amplification was repeated using the same word list read at the beginning of the session. A daily home practice program was included in the intervention. The program consisted of the current session's auditory bombardment word list and the child's production-practice words. His mother, who observed every clinical session, was instructed to read the auditory bombardment word list to her son, and to have the him name the picture cards of the production-practice words each day. His mother devoted approximately 2 minutes per day to the home program.

When the first cycle was completed, the APP-R was readministered to determine the progress made and to choose the 
phonological patterns that were targeted for the second cycle. The target phonological patterns and sounds are displayed in Table 3. A 100-word speech sample was collected to assess intelligibility gains made in the first cycle of intervention. The second cycle of intervention was conducted in the same manner as cycle one. Each

Table 3

Target Phonological Patterns and Sounds for Cycle 2

Target Phonological Patterns

Nasals

Stridency and Consonant

Sequences

Liquid (1)

Liquid ( $\mathrm{r}$ )
Target Sounds

initial $/ \mathrm{m}, \mathrm{n} /$, final $/ \mathrm{n} /$, and

medial $/ \mathrm{n} /$

$/ \mathrm{sk} /, \quad / \mathrm{sp}, \mathrm{st} /, \quad / \mathrm{ks}, \mathrm{ps} /$

initial /1/ and /pl/

initial $/ \mathrm{r} /$

60-minute session included the same elements as previously outlined.

Throughout the two intervention cycles, baseline measures were obtained at the beginning of each session. This measurement consisted of treatment and non-treatment words that contained target phonological patterns. In addition, probes were administered once a week. The probe consisted of treatment words, nontreatment words containing the targeted patterns, and words with nontargeted patterns. 
Reliability

Assessment of Phonological Processes-Revised. To establish reliability, the administration of the APP- $R$ was tape-recorded. The examiner used the audiotapes to verify or alter the live on-line transcriptions of the subject's responses on the APP-R. A second graduate speech-language pathology student independently listened to the audiotape and transcribed the subject's responses on the APP-R. When discrepancies existed between the APP-R transcriptions, the two examiners listened to the audiotape until an agreement of $95 \%$ was reached.

Speech Samples. Two graduate speech-language pathology students, other than the investigator, who were unfamiliar with the child, rated the child's intelligibility from the speech samples. Each of the 100-word speech samples was tape-recorded. The speech samples were presented to the raters in a random order. Each of the speech samples' intelligibility rating scores were averaged to achieve an overall rating score.

\section{Data Measurement and Analysis}

This study investigated the effectiveness of the phonological cycling approach in achieving a significant decrease in severity. A significant decrease in severity was defined as a decrease in severity level at the end of cycle two, when compared with the severity rating achieved on the initial APP-R. Thus, to be considered a significant decrease, the subject in this study needed to achieve a severity rating of severe at the end of cycle two, since his initial severity rating was profound. The severity rating and the 
percentage-of-occurrence scores were provided by the results of the pre-test and the post-tests of the APP- $R$ after cycle one and cycle two. These results provided a means for documenting improvements and for comparing and analyzing gains or losses in this area. In addition, the 100-word speech samples, collected at the beginning and end of each cycle, were rated using the sevenpoint rating scale. This intelligibility measure helped determine improvement in intelligibility after the two-cycle intervention period.

The four patterns targeted in both cycles of intervention were nasals, stridents/consonant sequences, liquid $/ 1 /$, and liquid $/ \mathrm{r} /$. Results from baselines, probes, and the APP- $R$ were presented in tables and figures to illustrate the effectiveness of the phonological cycling approach.

Results from the multiple baseline measures and the probes were utilized to assess the effectiveness of the approach and generalization. Each response in the baseline measurement and the probes was evaluated for accuracy of production regarding target and nontarget phonological patterns and words. Results of the multiple baseline were utilized to assess whether or not change was due to intervention. Results from the weekly probes contributed in determining the effectiveness of the intervention approach, measuring generalization into different words and sounds.

In summary, analysis of the results collected from pre- and post-testing, the weekly probes, multiple baseline measurements, and the intelligibility rating scales were descriptive in nature. The 
results were compared and analyzed to determine the effectiveness of the phonological cycling approach in achieving a decrease in severity level of intelligibility after two cycles. 


\section{CHAPTER IV \\ RESULTS AND DISCUSSION}

Results

In this study, the effectiveness of the phonological cycling approach in achieving a significant decrease in severity level after two cycles of intervention was investigated. The research hypothesis posed was: The phonological patterns cycling approach will lead to a significant decrease in severity level after two cycles of intervention as measured by pre- and post-testing on the APP-R and by an increased intelligibility rating.

Pre- and Post-Test Measures

The subject completed cycle 1 of the phonological cycling treatment approach in 5 weeks, during which he received 10 hours of direct intervention. Cycle 2 was completed in 4 1/2 weeks and he received 9 hours of direct intervention. A period of 7 weeks passed between the end of cycle 1 and the beginning of cycle 2 .

Phonological Process Analysis. The APP- $R$ was administered at the beginning of each cycle to obtain baseline data and to select the target patterns for treatment. The APP- $R$ was readministered at the end of each cycle to compare results obtained with baseline data and to determine if changes occurred in the percentage-ofoccurrence scores, the average of phonological processes, the deviancy score, and the severity interval. The phonological analysis summary is presented in Table 4, displaying pre- and post-cycle results for cycles 1 and 2 . 
Table 4

Pre- and Post-Cycle Results of the Computer Analysis of

Phonological Processes (CAPD) (Hodson, 1992b)

Phonological

Processes

Percentage-Of-Occurrence

Pre-Cycle Post-Cycle Pre-Cycle Post-Cycle

1 1 2

2

\section{OMISSIONS}

Syllables

11

5

5

0

Prevocalic Singletons

16

18

25

18

Postrocalic Singletons

35

32

29

32

Consonant Sequences

90

93

88

93

\section{CLASS DEFICIENCIES}

\begin{tabular}{lcccc} 
Stridents & 91 & 93 & 93 & 91 \\
Velars & 32 & 18 & 23 & 27 \\
Liquid (1) & 91 & 82 & 82 & 82 \\
Liquid (r) & 100 & 100 & 100 & 100 \\
Nasals & 89 & 58 & 53 & 53 \\
Glides & 70 & 80 & 80 & 50 \\
\hline
\end{tabular}

Average of

Phonological Processes 63 58 58 55

Phonological Deviancy

Score 63 58 58 55

Severity Interval Profound Severe Severe Severe
Note. The severity interval represents the deviancy score. Mild=1-19, moderate $=20-39$, severe $=40-59$, profound $=60 \&$ above. 
Results of the CAPD of the APP-R data indicate that the subject's severity interval decreased from profound to severe after the first cycle of treatment. In cycle 1, the percentage-ofoccurrence scores for the 10 basic phonological deviations increased for some deviations and decreased for others resulting in a net decrease of $5 \%$. Both the average of phonological processes and the phonological deviancy score decreased 5 points from 63 to 58 . Comparison of test results from post-cycle 1 with pre-cycle 2 indicate that the severity interval, average phonological processes, and phonological deviancy scores remained the same. Results from the APP-R at the end of cycle 2 indicate that the severity interval remained unchanged from cycle 1 , but a net decrease of 3 points occurred for the average of phonological processes and the phonological deviancy score.

Some changes in the percentage-of-occurrence for the four patterns targeted, that is nasals, stridents/consonant sequences, liquid $/ 1 /$, and liquid $/ \mathrm{r} /$, occurred between pre- and posttreatment. A significant decrease in the percentage-of-occurrence score for nasals occurred post-cycle 1 , resulting in a net decrease of 31 percentage points from 89 to 58 . Although a decrease of 5 points in percentage-of-occurrence scores occurred from post-cycle 1 to pre-cycle 2, further change did not occur following the second cycle of treatment. During the cycle 2 treatment period, percentage-of-occurrence scores for stridents and consonant sequences, decreased and increased, respectively. However, significant decreases in percentage-of-occurrence scores did not 
occur for these two phonological deviations. A decrease of 9 points in the percentage-of-occurrence score occurred for liquid /1/ after the first cycle of intervention. The percentage-of-occurrence score remained the same from post-cycle 1 to post-cycle 2 . Throughout the two cycle intervention period, the percentage-of-occurrence scores for liquid $/ \mathrm{r} /$ remained the same.

Speech Intelligibility. A 100-word speech sample was collected at the beginning and end of each cycle and rated on a 7 . point Likert rating scale. Table 5 displays the results of the speech intelligibility ratings. The subject was initially rated as 1 , essentially unintelligible. At the conclusion of the study he achieved a mean rating of 2.5 , an increase in intelligibility of 1.5 points on the 7-point scale.

Table 5

Intelligibility Ratings for Pre-and Post-Cycle 1 and 2

\begin{tabular}{|c|c|c|c|c|}
\hline & Pre-Cycle 1 & Post-Cycle 1 & Pre-Cycle 2 & Post-Cycle 2 \\
\hline Rater \#1 & 1 & 2 & 1 & 2 \\
\hline Rater \#2 & 1 & 2 & 1 & 3 \\
\hline $\begin{array}{l}\text { Average of } \\
\text { Ratings }\end{array}$ & 1 & 2 & 1 & 2.5 \\
\hline
\end{tabular}


Baseline Measures

Baseline measures were taken at the beginning of each treatment session on glides, a target pattern that had not received treatment. Four treatment words for each target pattern were included in the baseline measures. Two baseline measures were obtained for each target pattern prior to treatment in both cycle 1 and 2 .

Cycle 1. Figure 1 illustrates baseline measures for the nasal target sounds, initial $/ \mathrm{m} /$, initial $/ \mathrm{n} /$, and final $/ \mathrm{n} /$. With the exception of initial $/ \mathrm{n} /$ on day 1 and final $/ \mathrm{n} /$ of day 4 , the nasal target patterns were not present prior to treatment. Figure 2 displays baseline measures for the strident/consonant sequencetargets, $/ \mathrm{st} /, / \mathrm{sp} /, / \mathrm{sk} /$, and $/ \mathrm{ps} /$. None of the target

Dinitial $/ m /$ Dinitial $/ \mathrm{n} / \mathrm{final} / \mathrm{n} /$

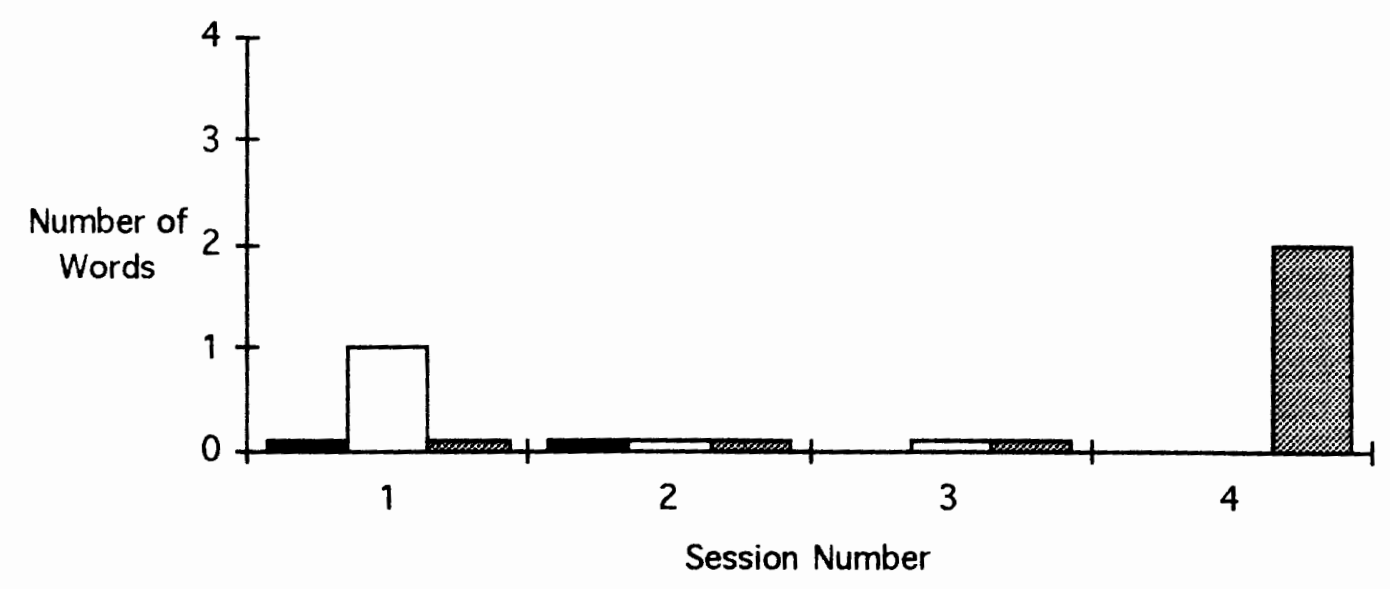

Figure 1. Cycle 1 Baseline for initial $/ \mathrm{m} /$, initial $/ \mathrm{n} /$, and final $/ \mathrm{n} /$. 
sounds were present before treatment except /sp/ on day 6 (1 of 4 words) and /ps/ ( 2 of 4 words) on day 9. Figure 3 displays baseline measures for initial $/ 1 /$ and initial /r/. While initial $/ \mathrm{r} /$ was not present prior to treatment, initial $/ 1 /$ was present in 1 of 4 words on days 5-9.

Cycle 2. Pre-cycle 2 baseline measures for target nasals, initial $/ \mathrm{m}, \mathrm{n} /$, final $/ \mathrm{n} /$, and medial $/ \mathrm{n} /$ are displayed in Figure 4. Results indicate that these target patterns were present prior to cycle 2 treatment. Initial $/ \mathrm{m}, \mathrm{n} /$ was used in 4 words on day 1 and in 3 words on day 2 . Final $/ \mathrm{n} /$ was used in 2 words on days 1-3.

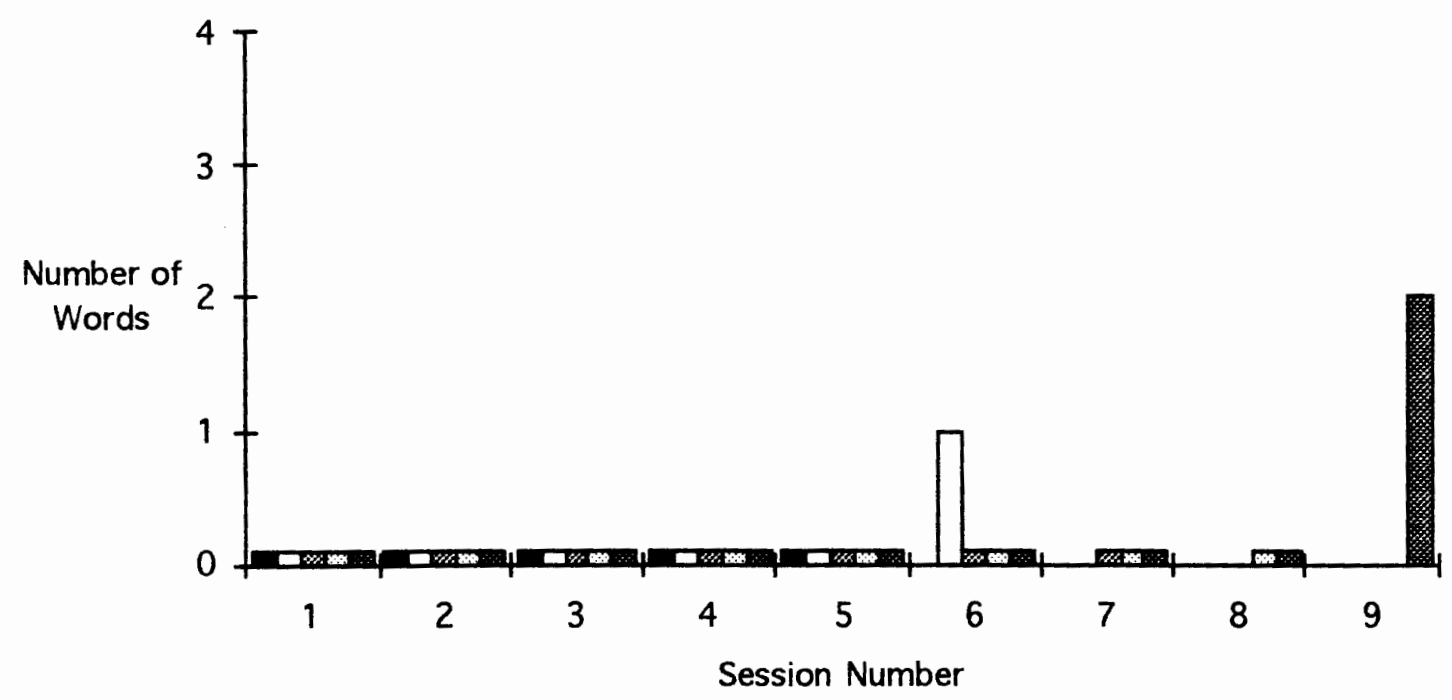

Figure 2. Cycle 1 Baseline for $/ \mathrm{st} /, / \mathrm{sp} /, / \mathrm{sk} /, / \mathrm{ks} /, / \mathrm{ps} /$. 


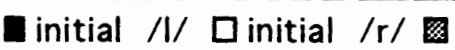

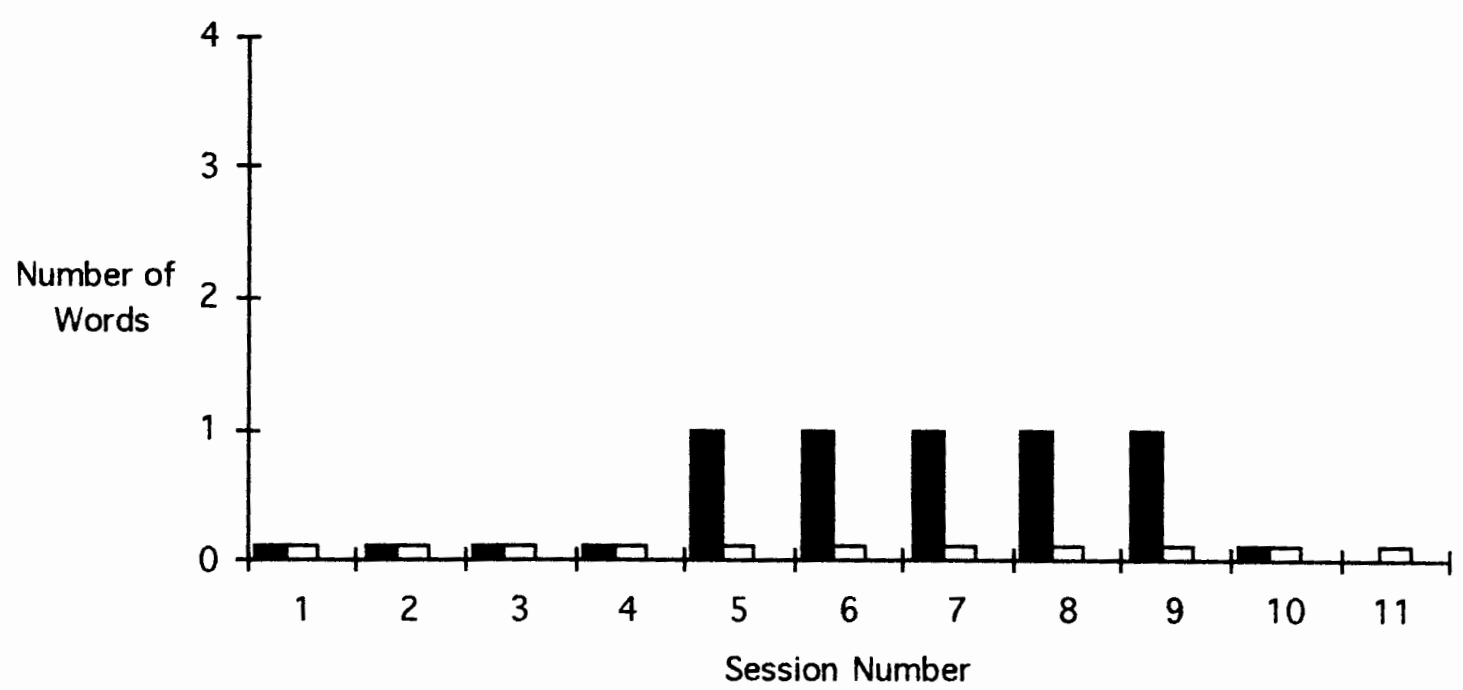

Figure 3. Cycle 1 Baseline for initial $/ 1 /$ and initial $/ \mathrm{r} /$.

Figure 5 illustrates pre-cycle 2 measures for the strident/consonant sequence targets, /sk/, /sp, st/, /ks, ps/. With the exception of /sp, st/ on days 2-6, little change in the target patterns occurred before treatment in cycle 2. Baseline measures for the $/ 1 /$ and $/ r /$ targeted patterns, initial $/ 1 /, / \mathrm{pl} /$, and initial $/ \mathrm{r} /$, are shown in Figure 6. Although initial $/ 1 /$ and $/ \mathrm{pl} /$ were present prior to the second cycle of treatment, the use was minimal (0-2 words). Initial $\mid \mathrm{r} /$ was not present before cycle 2 of treatment. 
Einitial $/ m, \mathrm{n} / \square$ final $/ \mathrm{n} /$ medial $/ \mathrm{n} /$

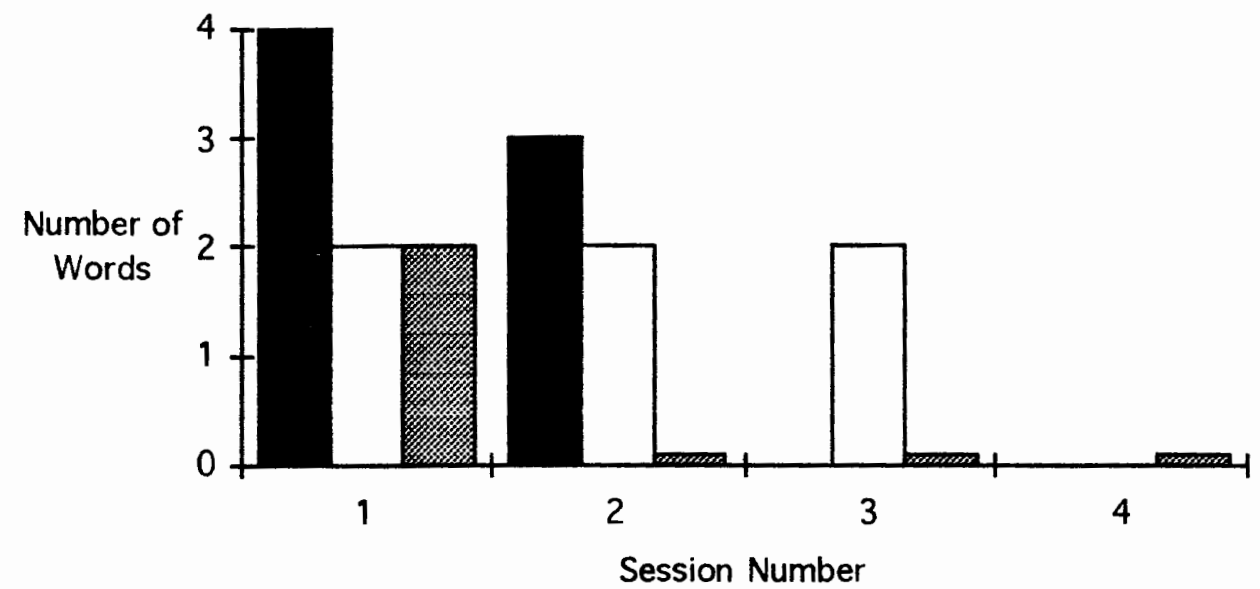

Figure 4. Pre-Cycle 2 Baseline for initial $/ \mathrm{m}$, $\mathrm{n} /$, final $/ \mathrm{n} /$, and medial $/ \mathrm{n} /$.

/sk/ $\mathrm{a} / \mathrm{sp}, \mathrm{st} / \mathrm{\theta} / \mathrm{ks}, \mathrm{ps} /$

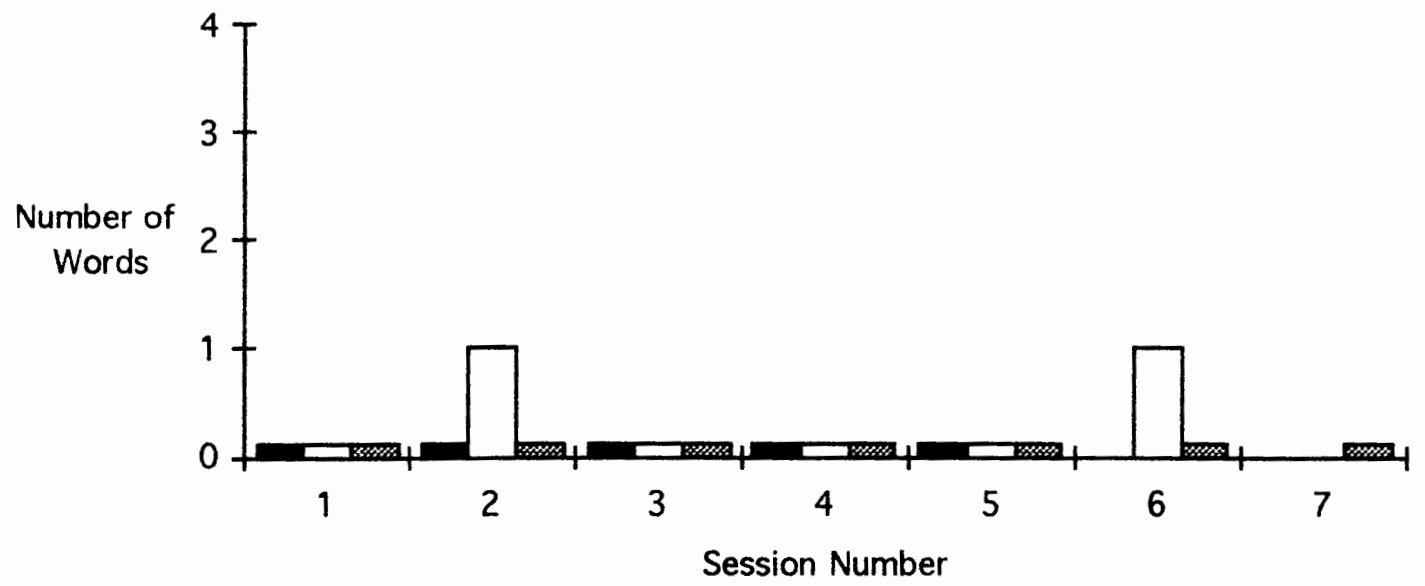

Figure 5. Pre-Cycle 2 Baseline for $/ \mathrm{sk} /$, /sp, st/, /ks, ps/. 


\section{Ginitial $/ / \mathrm{a} / \mathrm{pl} /$ Q initial $/ \mathrm{r} /$}

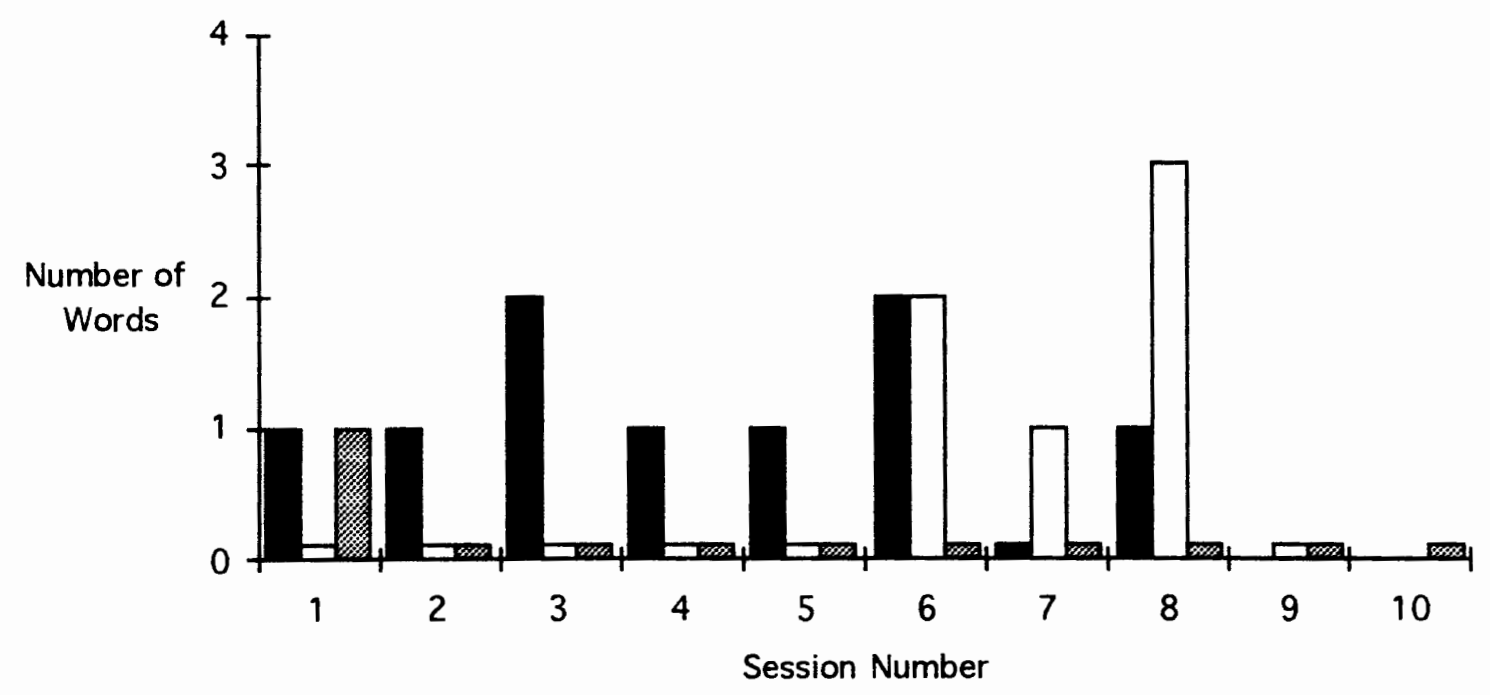

Figure 6. Pre-Cycle 2 Baseline for initial $/ 1 /, / \mathrm{pl} /$, and initial $/ \mathrm{r} /$.

\section{Probes}

Probes were administered weekly to determine the effectiveness of the intervention approach, and to measure the subject's generalization to untreated words and sounds. In Appendix $\mathrm{C}$, each session for both cycles are described, including the target sound, target words, and when the probes were administered. Table 6 displays the results of the probes for the first cycle and Table 7 shows the results for the second cycle.

For nasals, generalization to nontreatment words occurred after the pattern was treated, with an overall percentage of $91 \%$. On the final administration of the probe list, the target pattern was 
Table 6

Analysis of Cycle 1 Probe List With Treatment and Nontreatment Words and Patterns

\begin{tabular}{|c|c|c|c|c|c|c|c|c|c|c|c|c|c|}
\hline \multirow[b]{2}{*}{ Target } & \multirow[b]{2}{*}{ Patterns } & \multicolumn{2}{|c|}{ First } & \multicolumn{2}{|c|}{ Second } & \multicolumn{2}{|c|}{ Third } & \multicolumn{2}{|c|}{ Fourth } & \multicolumn{2}{|c|}{ Fifth } & \multicolumn{2}{|c|}{ Final } \\
\hline & & $\begin{array}{l}T X \\
n=2\end{array}$ & $\begin{array}{r}\text { NTX } \\
n=2\end{array}$ & $\begin{array}{l}\mathrm{TX} \\
\mathrm{n}=2\end{array}$ & $\begin{array}{r}\text { NTX } \\
n=2 \\
\end{array}$ & $\begin{array}{l}\mathrm{TX} \\
\mathrm{n}=2\end{array}$ & $\begin{array}{r}\text { NTX } \\
\mathbf{n}=2 \\
\end{array}$ & $\begin{array}{l}\mathrm{TX} \\
\mathrm{n}=2\end{array}$ & $\begin{array}{r}\text { NTX } \\
\mathrm{n}=2\end{array}$ & $\begin{array}{l}\mathrm{TX} \\
\mathrm{n}=2\end{array}$ & $\begin{array}{r}\text { NTX } \\
\mathrm{n}=2\end{array}$ & $\begin{array}{l}\text { TX } \\
n=2\end{array}$ & $\begin{array}{r}\text { NTX } \\
\mathrm{n}=2\end{array}$ \\
\hline \multicolumn{14}{|l|}{ Nasals } \\
\hline initial & $/ \mathrm{m} /$ & $1 *$ & 2 & 2 & 2 & 2 & 0 & 2 & 2 & 2 & 2 & 2 & 2 \\
\hline initial & $/ \mathbf{n} /$ & 0 & 1 & $2 *$ & 2 & 2 & 2 & 2 & 1 & 2 & 2 & 2 & 2 \\
\hline final & $/ \mathrm{n} /$ & 2 & 0 & $1^{*}$ & 0 & 1 & 1 & 1 & 1 & 2 & 2 & 2 & 1 \\
\hline
\end{tabular}

Stridency/

Consonant

Sequences

$\begin{array}{lllllllllllll}\text { / s / } & 0 & 0 & 0 & 0 & 2^{*} & 0 & 1 & 0 & 1 & 2 & 2 & 2 \\ \text { / s p / } & 0 & 0 & 0 & 0 & 0^{*} & 0 & 0 & 0 & 1 & 0 & 0 & 0 \\ \text { / s k / } & 0 & 0 & 0 & 0 & 0 & 0 & 0^{*} & 0 & 2 & 2 & 2 & 1 \\ \text { / k s/ } & 0 & 0 & 0 & 0 & 0 & 0 & 0^{*} & 0 & 2 & 0 & 2 & 2 \\ \text { /p s/ } & 0 & 0 & 0 & 0 & 0 & 0 & 0 & 0 & 1 & 1 & 2 & 2\end{array}$

Liquid $/ l l$

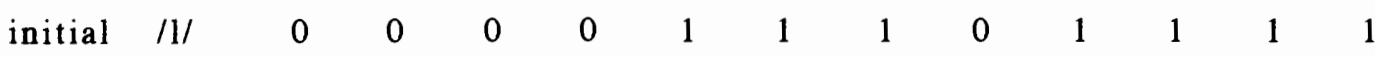

Liquid $/ r /$

\begin{tabular}{ccccccccccccc} 
initial $/ \mathrm{r} /$ & 0 & 0 & 0 & 0 & 0 & 0 & 0 & 0 & 0 & 0 & 0 & 0 \\
\hline Non-Target & & $\mathrm{n}=4$ & & $\mathrm{n}=4$ & & $\mathrm{n}=4$ & & $\mathrm{n}=4$ & $\mathrm{n}=4$ & $\mathrm{n}=4$
\end{tabular}

Patterns

\begin{tabular}{llllllll} 
initial $/ \mathrm{j} /$ & 0 & 0 & 4 & 4 & 4 & 3 \\
initial & $/ \mathrm{w} /$ & 0 & 0 & 0 & 2 & 1 & 1 \\
$/ \mathrm{kw} /$ & 0 & 0 & 0 & 0 & 0 & 2 \\
\hline
\end{tabular}

Note. ${ }^{*}$ indicates the first session after the pattern was targeted.

TX represent treatment words and NTX represents nontreatment words. $n=2$ indicates the number of words elicited under each condition for the target patterns. $n=4$ indicates the number of words elicited under each condition for the non-target patterns. 
used with $100 \%$ accuracy in initial $/ \mathrm{m} /$ and $/ \mathrm{n} /$, but final $/ \mathrm{n} /$ was $50 \%$ accurate.

Generalization to stridents/consonant sequences overall was $60 \%$, but inconsistent among the target sound combinations. Prior to treatment, there was no correct production of treatment words or nontreatment words. On the final administration of the probe list, generalization to nontreatment words with $100 \%$ accuracy occurred on $/ \mathrm{st} /, / \mathrm{ks} /$, and $/ \mathrm{ps} /, 50 \%$ on $/ \mathrm{sk} /$, and $0 \%$ on $/ \mathrm{sp} /$.

For the target pattern liquid $/ 1 /$, production of nontreatment words occurred prior to treatment; however, accuracy for treatment and nontreatment words never exceeded 50\%. Generalization to treatment and nontreatment words did not occur for liquid $/ r /$. Production of nontarget sounds was tracked for the following patterns: initial $/ \mathrm{j} /$, initial $/ \mathrm{w} /$, and $/ \mathrm{kw} /$. By the third probe, production of all 4 nontreatment words had occurred for initial $/ \mathrm{j} /$; however, only 3 of the words were produced correctly on the final probe. For initial $/ \mathrm{w} /$ and $/ \mathrm{kw} /$, production was poor.

Overall, generalization was the highest for the following patterns: nasals and strident/consonant sequences $(/ \mathrm{st} /, / \mathrm{ks} /$, and /ps/). Production of nontarget sounds was highest for initial $/ \mathrm{j} /$. Table 7 displays the results of the probes during cycle 2 . While nasals show excellent generalization to nontreatment words with $100 \%$ accuracy, stridency/consonant sequences showed only $33 \%$ production of treatment words and generalization to nontreatment words. Although both liquid /l/ sound targets show production of treatment words (100\%), generalization to 
Table 7

Analysis of Cycle 2 Probe List With Treatment and Nontreatment Words and Patterns

\begin{tabular}{|c|c|c|c|c|c|c|c|c|c|c|c|}
\hline \multirow[b]{2}{*}{ Target } & \multirow[b]{2}{*}{ Patterns } & \multicolumn{2}{|c|}{ First } & \multicolumn{2}{|c|}{ Second } & \multicolumn{2}{|c|}{ Third } & \multicolumn{2}{|c|}{ Fourth } & \multicolumn{2}{|c|}{ Final } \\
\hline & & $\begin{array}{l}\text { TX } \\
n=2\end{array}$ & $\begin{array}{r}\text { NTX } \\
n=2\end{array}$ & $\begin{array}{l}\text { TX } \\
n=2\end{array}$ & $\begin{array}{r}\text { NTX } \\
n=2 \\
\end{array}$ & $\begin{array}{l}\mathrm{TX} \\
\mathrm{n}=2 \\
\end{array}$ & $\begin{array}{r}\text { NTX } \\
\mathrm{n}=2 \\
\end{array}$ & $\begin{array}{l}\mathrm{TX} \\
\mathrm{n}=2\end{array}$ & $\begin{array}{r}\text { NTX } \\
\mathrm{n}=2\end{array}$ & $\begin{array}{l}\mathrm{TX} \\
\mathrm{n}=2\end{array}$ & $\begin{array}{r}\text { NTX } \\
n=2\end{array}$ \\
\hline \multicolumn{12}{|l|}{ Nasals } \\
\hline & initial $/ \mathbf{m}, \quad \mathbf{n} /$ & $2 *$ & 2 & 2 & 2 & 2 & 2 & 2 & 2 & 2 & 2 \\
\hline & final $/ \mathrm{n} /$ & 2 & 1 & $2 *$ & 1 & 2 & 2 & 2 & 2 & 2 & 2 \\
\hline & medial $/ \mathrm{n} /$ & 1 & 0 & $2 *$ & 2 & 2 & 1 & 2 & 2 & 2 & 2 \\
\hline
\end{tabular}

Stridency/Consonant

Sequences

$\begin{array}{lllllllllll}/ \mathrm{sk} / & 0 & 0 & 0 & 1 & 0^{*} & 1 & 0 & 0 & 1 & 1 \\ / \mathrm{st}, \quad \mathrm{sp} / & 0 & 0 & 0 & 0 & 1^{*} & 0 & 0 & 0 & 1 & 0 \\ / \mathrm{ks}, \mathrm{ps} / & 0 & 0 & 0 & 0 & 1 & 0 & 0 * & 0 & 1 & 0\end{array}$

Liquid $/ l /$

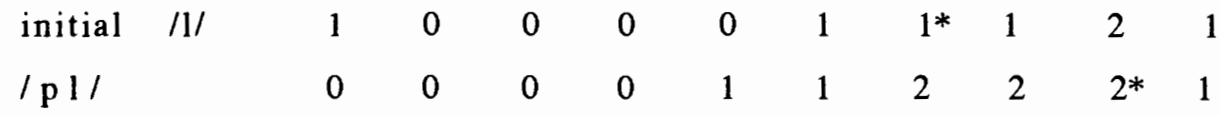

Liquid $/ r /$

\begin{tabular}{|c|c|c|c|c|c|c|}
\hline & initial $/ \mathrm{r} /$ & 0 & 0 & 0 & 0 & 0* \\
\hline \multirow[t]{4}{*}{ Non-Targe } & Patterns & $n=4$ & $n=4$ & $n=4$ & $n=4$ & $\mathrm{n}=4$ \\
\hline & initial $/ \mathrm{j} /$ & 2 & 1 & 2 & 4 & 4 \\
\hline & initial $/ w /$ & 2 & 2 & 2 & 2 & 2 \\
\hline & $|\mathrm{k} \mathrm{w}|$ & 1 & 0 & 1 & 0 & 0 \\
\hline
\end{tabular}

Note. * indicates the first session after the pattern was targeted.

TX represent treatment words and NTX represents nontreatment words. $n=2$ indicates the number of words elicited under each condition for the target patterns. $n=4$ indicates the number of words elicited under each condition for the non-target patterns.

nontreatment words was poor $(50 \%)$. Generalization to nontreatment words for liquid $/ r /$ did not occur. For nontarget patterns, initial $/ \mathrm{j} /$ shows excellent production with $100 \%$ accuracy 
even though it was not targeted. Although initial $/ \mathrm{w} /$ and $/ \mathrm{kw} /$ had poor production, they did go from 0 correct productions to 1 or 2 correct productions throughout the course of treatment. Overall, generalization was the highest for the targeted nasals and the nontargeted initial $/ \mathrm{j} /$.

\section{Discussion}

The results of this study indicate that a significant decrease in severity level after one cycle of intervention was achieved with the phonological cycling approach for this subject. A significant decrease in severity was defined as one severity level rating lower at the end of cycle two than the severity rating achieved on the initial APP-R. This subject achieved a severity rating of severe at the end of cycle 1 , as well as at the end of cycle 2 , compared to his initial severity rating of profound. Although it was hypothesized that 2 cycles of intervention would be needed, one cycle was enough to achieve a decrease in severity level for this subject. Additionally, over the 2-cycle treatment period, the results of the CAPD indicated a general decrease in percentage-of-occurrence scores, average of phonological deviations, and phonological deviancy scores. In the first cycle of intervention, significant decreases occurred for liquid /1/ deficiency and nasal deficiency, two patterns targeted during cycle 1. Significant decreases in percentage-of-occurrence scores did not occur for the other two deficient patterns that were targeted, that is, strident/consonant sequences and liquid $/ r /$. For cycle 2 , a significant decrease 
occurred for glide deficiency $(j, w)$, even though this pattern was not targeted.

Overall, the most clinically significant decreases occurred post-cycle 1. At this point, CAPD results indicated a decrease in severity interval from profound to severe. This finding is not consistent with Hodson and Paden's (1991) contention that significant change should not be expected after only one cycle of intervention. Rather, they stated that change usually occurs during cycle 2 .

A reason for the findings of this study might be that the subject received treatment more frequently than in Hodson's program (Mary Gordon-Brannan, personal communication, March 8, 1995). Hodson sees clients once a week for 60 to 90 minutes, whereas the subject in this study was seen for an hour twice a week for a weekly total of 120 minutes. Although the severity interval rating for cycle 2 remained the same, average of phonological deviations and phonological deviancy scores did decrease slightly. Overall, dramatic change in terms of correct sound production did not occur, even though a minimal decrease in severity interval rating was noted.

Baseline measures indicate that the subject produced a few target sounds correctly prior to treatment. The only pattern that did show correct production prior to treatment was nasals prior to the initiation of cycle 2. The correct productions of the nasal pattern prior to treatment may be attributed to the fact that these nasal sounds were targeted in cycle 1. In addition, they represent 
the first pattern targeted, and they are earlier developing sounds. Overall, minimal correct productions of target patterns in cycle 1 and 2 occurred prior to treatment.

Results of the probes were used to determine the effectiveness of treatment and to measure the subject's generalization to untreated sounds and words. In cycle 1, generalization was highest for the targeted nasal sounds, /st/, /ks/, and $/ \mathrm{ps} /$, and for the nontargeted $/ \mathrm{j} /$. Generalization to nontreatment words for the other targeted and nontargeted patterns was either less than $50 \%$ or did not occur. Again, in cycle 2, generalization to nontreatment words was highest for nasals and the nontargeted pattern $/ \mathrm{j} /$. For the other targeted and nontargeted patterns, generalization was either poor or did not occur. Overall, generalization to nontreatment words was the highest for nasals, and production of nontargeted patterns was the highest for $/ \mathrm{j} /$. Although maximum stability to targeted patterns was not achieved, as indicated by the probes, some improvement was noted. The subject did exhibit some use of target patterns in nontreatment words in targeted and nontargeted patterns.

Although $/ \mathrm{j} /$ was not targeted in treatment, a significant change occurred for this pattern. There are a number of reasons why this could have occurred. First, $/ \mathrm{j} /$ is an early developing sound and treating the other patterns might have stimulated the glides. Also, the subject was inadvertently exposed to $/ \mathrm{j} /$. During each session, the subject colored pictures of the treatment words. As he put the colored markers away, he would say each color with 
the examiner modeling the correct pronunciation. The subject said /tio/ for /jEloU/ during cycle 1 and the beginning of cycle 2; however, towards the end of cycle 2 , he began to say $/ \mathrm{jEo} /$. As a result, this inadvertent exposure might account for the change.

Speech intelligibility gains were noted both in conversational speech and in the results of the APP-R. On the post-test of cycle 2 of the APP-R, the subject produced fewer omissions and substitutions. This probably affected his intelligibility. In addition, the final 100-word speech sample indicated an increase in intelligibility of 1.5 points on a 7-point Likert scale.

The speech of this subject has improved. This was reflected in the decrease in percentage-of-occurrence scores, the decrease in severity interval, his improved speech intelligibility, generalization to nontreatment words, and production of nontargeted patterns. Presumably, the result of his improvement is due to the phonological cycling approach.

Although the subject's speech has improved as indicated by the increase in speech intelligibility and the decrease in severity interval, other clinical changes on specific words were also noted that were not apparent on the APP-R or intelligibility rating. For example, at the beginning of cycle 1 the subject called his mother b a. In the middle of cycle 2 , he began saying mom. This change was extremely significant to the family and its importance can not be quantified on any type of scale. 


\section{Other Considerations}

Although the phonological cycling approach probably facilitated the greatest amount of change in the subject's intelligibility, there are other possibilities that must be considered. The age of the subject might have influenced the outcome. The subject was $3 \quad 1 / 2$ years old when the study began and 4 years old when it ended. His age added to his emotional, physical, and mental maturity might have been the right combination needed to achieve the intelligibility gains.

Time-off between the two cycles may also be a factor. The 7 weeks between the two cycles may have allowed the subject extra time to process what he had learned. Hodson encourages time-off between cycles allowing time for the brain to process and incorporate the new phonological patterns (Mary Gordon-Brannan, personal communication, March 8, 1995). In addition, general development was occurring during this time and that may have influenced his increases in intelligibility.

Another factor may have been related to the subject's and his mother's willingness to be active participants in his intervention. There were not any behavioral concerns, and the subject was attentive and wanted to say his words correctly. In addition, his mother was very supportive. She was conscientious in completing the daily homework assignments and was willing to be involved in his intervention program. 
In summary, results from this study indicate that the phonological cycling approach was effective in achieving a decrease in severity level after two cycles of intervention for this subject. 


\section{CHAPTER V}

\section{SUMMARY AND IMPLICATIONS}

Summary

One preschool male who was highly unintelligible was enrolled in two cycles of direct intervention utilizing the phonological cycling approach (Hodson \& Paden, 1991). Prior to treatment the subject was administered the Assessment of Phonological Processes-Revised (APP-R; Hodson, 1986) to assess the subject's phonological deficiencies and to determine the target phonological patterns. A continuous speech sample was collected prior to cycle 1 to measure speech intelligibility on a 7-point Likert rating scale. Based on the results obtained from the APP-R, target patterns and words and an individualized treatment plan were developed.

For the first cycle of intervention, the subject participated in 60 minutes of direct intervention twice a week for 5 weeks. Each session included the administration of baseline measures and the cycling approach procedures as outlined by Hodson and Paden (1991). Probes were administered weekly. At the conclusion of cycle 1, the APP-R was re-administered and a 100-word speech sample was collected.

Prior to the second cycle, a speech sample was collected and the APP-R was administered to assess improvement and to determine the target phonological patterns. Target patterns and words were developed based on the results. In cycle 2 , the subject participated in 60 minutes of direct intervention twice a week for 4 
$1 / 2$ weeks. Each session followed the same procedures as in cycle 1. At the conclusion of cycle 2, the APP-R was re-administered and a speech sample was collected.

The results of the pre- and post-tests for cycles 1 and 2, baseline measures, weekly probes, and the intelligibility ratings were analyzed to determine the effectiveness of the phonological cycling approach in achieving a decrease in severity level of unintelligibility after two cycles. Results from the APP-R indicate that the subject's severity interval rating decreased from profound to severe. A comparison of pre- and post-intelligibility ratings showed an increase in intelligibility of 1.5 point on a 7-point Likert scale. Based on the probes, generalization to nontreatment words in targeted patterns and production of nontargeted patterns was noted in both cycles for some patterns. Overall, the phonological cycling approach was effective in achieving a decrease in severity level of intelligibility after two cycles of intervention for this subject.

\section{Implications}

Based on the results from this study, several implications can be drawn. First, findings from this study suggest that the phonological cycling approach is effective in achieving a decrease in severity level in intelligibility after two cycles of intervention for this child. Although two cycles were not effective in achieving complete intelligibility for this subject, a decrease in severity level was achieved. It might be hypothesized that for most highly unintelligible children, as for this child, two cycles of the phonological cycling approach will not be enough. While the two 
cycles appear to lay the phonological foundation, a third and even a fourth cycle may be necessary to provide additional exposure to the target patterns that have not begun to emerge in conversational speech (Hodson \& Paden, 1991).

Since assessing generalization can be problematic, the use of probes may or may not provide an accurate measure of generalization to nontreatment and nontargeted words. Further investigation into other measures of carryover may be necessary. In addition, the number of words included in the probe and the manner in which the words are elicited may need to be changed in order to measure generalization more effectively. Parental reports may prove to be a useful technique in obtaining information regarding generalization and communicative abilities in a more natural setting.

Based on the results of this study, several research ideas can be considered. Single-subject multiple baseline experimental design studies using the phonological cycling approach with both girls and boys who are highly unintelligible would be beneficial. In addition, studies are needed that compare the results obtained from the cycling approach to other phonological and articulation approaches utilized with children who are highly unintelligible. Although a study investigating the effectiveness of the cycling approach with groups was conducted (Montgomery \& Bonderman, 1989), further research into this area is warranted. Since both individual and groups can be used with the cycling approach, is one more effective than the other? 
Children with disabilities, such as Down Syndrome and cleft palate, may be highly unintelligible. Given the severity of the disorder, would the phonological cycling approach be an effective treatment approach? In addition, children with hearing impairments may be highly unintelligible. Would the cycling approach be effective in achieving intelligibility with children who are hearing impaired? Since auditory bombardment is included in the approach, are modifications needed for these children?

Data regarding the efficacy of intervention approaches, including the phonological cycling approach with highly unintelligible children, are lacking. Since children who are highly unintelligible often experience difficulty academically and socially, there should be an urgency in seeking to eliminate or reduce significantly the communication problems that these children face. Therefore, is the cycling approach effective and efficient in reducing communication problems? In addition, phonological intervention approaches need to be efficient to reduce the contact time for both the clinician and client. Does the cycling approach reduce clinicianclient contact time? According to Hodson and Scudder (1990), factors such as severity, hours of contact time, and generalization to nontreatment words and patterns must be considered.

Because speech-language pathologists provide treatment to children who are unintelligible, it is important to continue searching for more effective and efficient methods for achieving intelligibility. Currently, the phonological cycling approach appears to be an effective and efficient approach; however, more efficacy research 
studies are needed in order to determine if the cycling approach is the most effective and efficient method in reducing the potential handicapping effects of unintelligible speech.

The focus of this study was to investigate the effectiveness of the phonological cycling approach in achieving a decrease in severity level of intelligibility after two cycles of intervention. Although the results indicated that the approach was effective for the subject who participated in this study, further research is needed with more subjects to support or reject the findings. The subject who participated in the study continued to receive treatment using the same approach. He is currently receiving treatment in cycle 4. 


\section{References}

Dunn, L. M., \& Dunn, L. M. (1981). Peabody picture vocabulary test-revised. Circle Pines, MN: American Guidance Service.

Fey, M. E. (1992). Articulation and phonology: Inextricable constructs in speech pathology. Language, Speech, and Hearing Services in Schools, 23, 225-232.

Gierut, J. A. (1990). Differential learning of phonological oppositions. Journal of Speech and Hearing Research, 33, 540-549.

Gordon-Brannan, M. (1994). Assessing intelligibility:

Children's expressive phonologies. Topics in Language Disorders, 14 , 17-25.

Hodson, B. A. (1986). The assessment of phonological processes-revised. Austin, TX: ProEd.

Hodson, B. A. (1992a). Applied phonology: Constructs, contributions, and issues. Language, Speech, and Hearing Services in Schools, 23. 247-253.

Hodson, B. A. (1992b). Computer analysis of phonological deviations. Stonington, IL: PhonoComp Software.

Hodson, B. A., \& Paden, E. P. (1981). Phonological processes which characterize unintelligible and intelligible speech in early childhood. Journal of Speech and Hearing Disorders, 46. 369-373.

Hodson, B. A., \& Paden, E. P. (1991). Targeting intelligible speech: A phonological approach to remediation (2nd ed.). Austin, TX: ProEd.

Hodson, B. A., \& Scudder, R. R. (1990). Phonological disorders in children. Seminars In Speech and Language, 11, 192-199. 
Kent, R. D. (1991). Forward. In B. W. Hodson \& E. P. Paden, Targeting intelligible speech (2nd ed.). Austin, TX: ProEd.

Montgomery, J. K., \& Bonderman, I. R. (1989). Serving preschool children with severe phonological disorders. Language. Speech, and Hearing Services in Schools, 20, 76-84.

Saben, C. B., \& Ingham, J. C., (1991). The effects of minimal pairs treatment on the speech-sound production of two children with phonological disorders. Journal of Speech and Hearing Research, 34, 1023-1040.

Shriberg, L. D., \& Kwiatkowski, J. (1982). Phonological disorders III: A procedure for assessing severity of involvement. Journal of Speech and Hearing Disorders, 47. 256-270.

Tyler, A. A., Edwards, M. L., \& Saxman, J. H. (1987). Clinical application of two phonologically based treatment procedures. Journal of Speech and Hearing Disorders, 52, 393-409.

Weiner, F. (1981). Treatment of phonological disability using the method of meaningful minimal contrast: Two case studies. Journal of Speech and Hearing Disorders, 46, 97-103.

Weiss, C. E., Gordon, M. E., \& Lillywhite, H. S. (1987). Clinical management of articulatory and phonologic disorders. Baltimore, MD: Williams \& Wilkins.

Weston, A. D., \& Shriberg, L. D. (1992). Contextual and linguistic correlates of intelligibility in children with developmental phonological disorders. Journal of Speech and Hearing Research, $\underline{35}$ $1316-1332$. 
APPENDIX A

INFORMED CONSENT 


\section{INFORMED CONSENT}

I, _____________ the caregiver of hereby agree to allow my child to serve as a

subject for the investigation of: The Effectiveness of the Phonological Processes Cycling Approach in Treating Unintelligible Children in the First Two Cycles of Intervention. This study is conducted under the supervision of Mary Gordon-Brannan.

I understand that this study involves my child's participation in an intervention technique designed to improve his speech intelligibility. The Phonological Cycling Approach, which is designed to reduce the frequency of occurrence of certain phonological processes that contribute to intelligibility, will be the intervention approach utilized for this study. The techniques used in this approach are standard speech treatment techniques. It has been explained to me that the purpose of this study is to learn if the cycling approach will improve the speech intelligibility of unintelligible children in the first two cycles of intervention.

I understand that the time commitment for this study involves my time of 60 minutes of intervention 2 times a week. Intervention will be approximately 20 weeks in length and will be divided into 2 cycles of about 10 weeks each. I will also be expected to spend 2 to 3 minutes a day on a home practice program with my child.

I understand that there is no risk involved in this study. The only inconvenience involves my time of 60 minutes of intervention 2 times a week. My child will receive two cycles of intervention that will be approximately 10 weeks in length each. In addition, I will have to spend 2 to 3 minutes a day on a home practice with my child.

My child may not receive any direct benefit from participation in this study, but our participation in this study may help to increase knowledge which may benefit others in the future.

Anne Cole has offered to answer any questions I may have about the study and what is expected of me and my child in the 
study. I have been promised that all information I give will be kept confidential and that the identity of my child will remain anonymous.

I have read and understand the above information and agree to my child's participation in the study. I am aware that we are at liberty to withdraw from the study at any time.

Child's Name

Signature

Date

Witness

Date

If you have concerns or questions about this study, please contact Anne Cole, (503)2245-8764, or the Chair of the Human Subjects Research Review committee, Office of Research and Sponsored Projects, 105 Neuberger Hall, Portland State University, (503)725-3417. 
APPENDIX B

RATING SCALE FOR INTELLIGIBILITY 


\section{Rating Scale for Intelligibility}

\begin{tabular}{ccccccc}
$\begin{array}{l}\text { Essentially } \\
\text { Unintelligible }\end{array}$ & & $\begin{array}{l}\text { Sometimes } \\
\text { Intelligible }\end{array}$ & & \multicolumn{2}{c}{$\begin{array}{c}\text { Essentially } \\
\text { Intelligible }\end{array}$} \\
1 & 2 & 3 & 4 & 5 & 6 & 7
\end{tabular}


APPENDIX C

EACH SESSION'S TARGET SOUND AND WORDS FOR CYCLE 1 AND 2 
Table A-1

Cycle 1: Each Session's Target Sound and Words

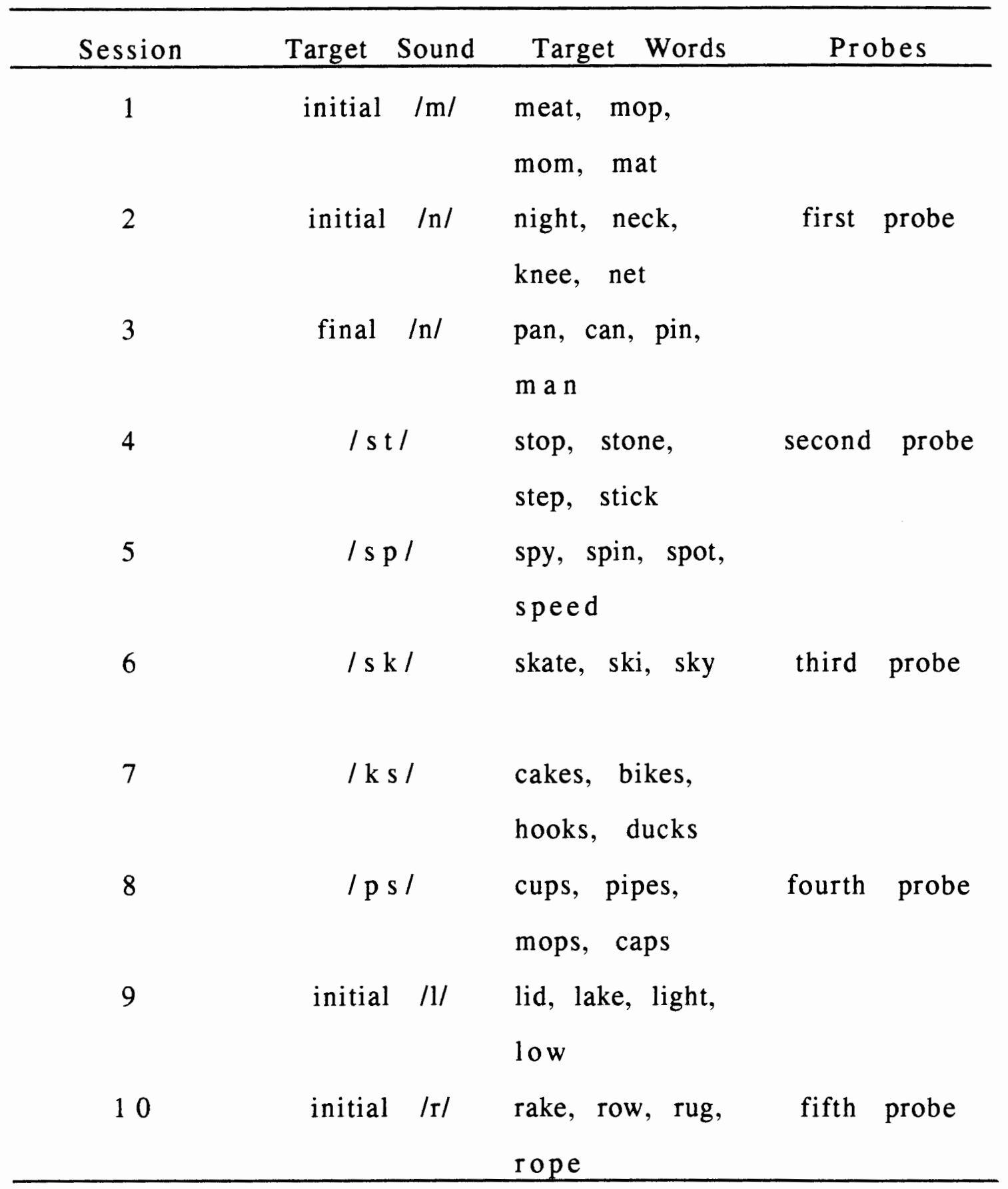


Table A-2

Cycle 2: Each Session's Target Sound and Words

\begin{tabular}{|c|c|c|c|c|}
\hline Session & Target Sound & Target Words & \multicolumn{2}{|c|}{ Probes } \\
\hline 1 & initial $/ \mathrm{m}, \mathrm{n} /$ & $\begin{array}{l}\text { mop, mud, nut, } \\
\text { knock }\end{array}$ & & \\
\hline 2 & final $/ \mathrm{n} /$ & $\begin{array}{l}\text { pan, can, moon, } \\
\text { m a n }\end{array}$ & first & probe \\
\hline 3 & medial $/ \mathrm{n} /$ & $\begin{array}{l}\text { bunny, penny, } \\
\text { canoe, pony }\end{array}$ & & \\
\hline 4 & / s k / & $\begin{array}{l}\text { sky, skip, skate, } \\
\text { ski }\end{array}$ & second & probe \\
\hline 5 & $/ \mathrm{sp}, \quad \mathrm{st} /$ & $\begin{array}{l}\text { spy, spot, stop, } \\
\text { stone }\end{array}$ & & \\
\hline 6 & $/ \mathrm{ks}, \quad \mathrm{ps} /$ & $\begin{array}{l}\text { cakes, books, } \\
\text { cups, pups }\end{array}$ & third & probe \\
\hline 7 & initial /1/ & $\begin{array}{l}\text { lip, lake, light, } \\
\text { low }\end{array}$ & & \\
\hline 8 & $/ \mathrm{p} 1 /$ & $\begin{array}{l}\text { plate, play, } \\
\text { plum. }\end{array}$ & fourth & probe \\
\hline 9 & initial $/ \mathrm{r} /$ & $\begin{array}{l}\text { red, rat, rake, } \\
\text { row }\end{array}$ & & \\
\hline
\end{tabular}

